Original Research Communication

\title{
High copper complex stability and slow reduction kinetics as key \\ parameters for improved activity, paraptosis induction and impact on drug-resistant cells of anticancer thiosemicarbazones
}

Sonja Hager, ${ }^{1,2 \$}$ Veronika F.S. Pape, ${ }^{3,4 \$}$ Vivien Pósa, ${ }^{5,6}$ Bianca Montsch, ${ }^{1,2}$ Lukas Uhlik, $^{1,2}$ Gergely Szakács, ${ }^{1,3}$ Szilárd Tóth, ${ }^{3}$ Nikolett Jabronka, ${ }^{3}$ Bernhard K. Keppler, ${ }^{2,7}$ Christian R. Kowol, ${ }^{2,7}$ Éva A. Enyedy, ${ }^{5,6^{*}}$ Petra Heffeter, ${ }^{1,2^{*}}$

${ }^{1}$ Institute of Cancer Research, Medical University of Vienna, Borschkegasse 8a, A-1090 Vienna, Austria

${ }^{2}$ Research Cluster 'Translational Cancer Therapy Research', A-1090 Vienna, Austria

${ }^{3}$ Institute of Enzymology, Research Centre for Natural Sciences, Hungarian Academy of Sciences, Magyar Tudósok körútja 2, H-1117 Budapest, Hungary

${ }^{4}$ Department of Physiology, Semmelweis University, Túzoltó utca 37-47, H-1094 Budapest, Hungary

${ }^{5}$ Department of Inorganic and Analytical Chemistry, Interdisciplinary Excellence Centre, University of Szeged, Dóm tér 7, H-6720 Szeged, Hungary

${ }^{6}$ MTA-SZTE Lendület Functional Metal Complexes Research Group, University of Szeged, Dóm tér 7, H-6720 Szeged, Hungary

${ }^{7}$ Institute of Inorganic Chemistry, Faculty of Chemistry, University of Vienna, Waehringer Str. 42, A-1090 Vienna, Austria

$\$$ These authors contributed equally to the main findings of this manuscript.

Running title: Insights into the MoA of nM TSCs

Keywords: solution stability, thiosemicarbazones, copper complexes, protein disulfide isomerase, paraptosis, superoxide dismutase

Authors for correspondence: University of Szeged, Department of Inorganic and Analytical Chemistry, Interdisciplinary Excellence Centre, Dóm tér 7, H-6720 Szeged, Hungary. Phone: +36-62-544334. E-mail: enyedy@chem.u-szeged.hu 
Medical University of Vienna, Institute of Cancer Research, Borschkeg. 8a, A-1090 Vienna, Austria. Phone: +43-1-40160-57594. Fax: +43-1-40160-957555. E-mail:

훈. petra.heffeter@meduniwien.ac.at.

Word count: 8172 (incl. Abstract, Introduction, Results, Discussion, Materials \& Methods) References: 60

Greyscale illustrations: 4 Color illustrations: 1 
Abstract

Aims: Due to their significant biological activity, thiosemicarbazones (TSCs) are promising candidates for anticancer therapy. In part, the efficacy of TSCs is linked to their ability to chelate essential metal ions such as copper and iron. Triapine, the best-studied anticancer TSC, has been tested clinically with promising results in hematological diseases. During the last years, a novel subclass of TSCS with improved anticancer activity was found to induce paraptosis, a recently characterized form of cell death. The aim of this study was to identify structural and chemical properties associated with anticancer activity and paraptosis induction of TSCs.

Results: When testing a panel of structurally related TSCs, compounds with nanomolar anticancer activity and paraptosis-inducing properties showed higher copper(II) complex solution stability and a slower reduction rate, which resulted in reduced redox activity. In contrast, TSCs with lower anticancer activity induced higher levels of superoxide that rapidly stimulated superoxide dismutase expression in treated cells, effectively protecting the cells from drug-induced redox stress.

Innovation: Consequently, we hypothesize that in case of close Triapine derivatives, intracellular reduction leads to rapid dissociation of intracellularly formed copper complexes. In contrast, TSCs characterized by highly stable, slowly reducible copper(II) complexes are able to reach new intracellular targets such as the ER-resident protein disulfide isomerase.

Conclusions: The additional modes of actions observed with highly active TSC derivatives are based on intracellular formation of stable copper complexes, offering a new approach to combat (drug-resistant) cancer cells. 


\section{Introduction}

Thiosemicarbazones (TSCS) possess significant biological activity, which resulted in their development as pharmaceuticals against several diseases, including cancer (24). In part, the efficacy of TSCs is linked to their ability to chelate essential metal ions such as copper and iron. Cancer cells, in particular, require higher amounts of these metal ions due to their increased rate of replication $(3,60)$. As a result, the ability of $\alpha-N$-heterocyclic TSCs to form stable metal complexes is an important property for their development as anticancer agents (26).

Initially, the mechanism of action of $\alpha-N$-heterocyclic TSCs was thought to primarily rely on the depletion of iron and the consequential inhibition of the iron-containing enzyme ribonucleotide reductase (57). However, the role of other metals (especially copper), metalloenzymes and metal-interacting proteins is gaining more attention $(16,22)$. For example, the ability of copper(II)-TSC complexes to undergo redox cycling in the presence of reducing agents, with production of reactive oxygen species (ROS) (a process also called "activation by reduction" (22)), and the disruption of the cellular thiol redox homeostasis is increasingly discussed as relevant contributions to TSC activity $(11,23,27,44)$. Furthermore, the interaction with copper ions has been recently suggested to be involved in collateral sensitivity of P-glycoprotein (P-gp, $\mathrm{ABCB} 1$ )-overexpressing multidrug-resistant cancer cells to the nanomolar-active TSC di-2-pyridylketone 4,4-dimethyl-3-thiosemicarbazone (Dp44mT) (21). Interestingly, recently performed studies confirmed the enhanced sensitivity of certain P-gp-overexpressing cells (e.g. MES-SA/Dx5) to several metal chelators (including Dp44mT), but also suggested that the collateral sensitivity of these MDR cells may rely on other (more complex) mechanisms independent of P-gp transport function $(9,40)$.

With regard to the clinical situation, the best studied anticancer TSC, Triapine, has been already tested in several phase I and II trials with promising results especially against hematological diseases $(12,25,54,56,59)$. Currently, this drug is being investigated as chemo- and radiosensitizer in an ongoing clinical phase III study assessing Triapine in combination with cisplatin and radiation therapy (NCT02466971) (30). In addition, two other $\alpha$-N-heterocyclic TSCs di-2-pyridylketone 4-cyclohexyl-4-methyl-3thiosemicarbazone (DpC) and 4-(pyridine-2-yl)-N-\{[(8E)-5,6,7,8-tetrahydroquinolin-8- 
ylidene]amino\})piperazine-1-carbothioamide (Coti-2) recently entered clinical phase I trials (www.clinicaltrials.gov). Noteworthy, these two compounds as well as Dp44mT (the predecessor of $\mathrm{DpC}$ ) and our dimethylated Triapine derivative $\mathrm{Me}_{2} \mathrm{NNMe}_{2}$ represent a subclass of TSCs characterized by a $\sim 500$-fold higher anticancer activity compared to Triapine in cell culture $(20,37)$. Recent studies suggested that this efficiency could be based on an additional mode-of-action, associated with the formation of intracellular copper complexes $(16,19,34)$. In particular, our group discovered that these compounds are able to induce paraptosis, a novel form of programmed cell death (13). Paraptosis is a caspaseindependent cell death discernable by the appearance of cytoplasmic vesicles originating from the endoplasmic reticulum (ER) $(33,50)$. TSC-induced paraptosis appears to be associated with the (copper-dependent) inhibition of the ER-resident protein disulfide isomerase (PDI) (13). In light of these recent data, the aim of this study was to elucidate the role of copper complex formation of various TSCs in anticancer activity, paraptosis induction and collateral sensitivity. For this purpose, we investigated solution stability and redox properties of a selected panel of structurally related $\alpha-N$-heterocyclic TSCs and their respective copper(II) complexes. The measured physico-chemical properties were then correlated with biological parameters (anticancer activity, resistance ratio of multidrugresistant (MDR) cancer cells, paraptosis induction and PDI inhibition). Thus, we show that highly active TSCs (with $\mathrm{IC}_{50}$ values in the nanomolar range) form copper(II) complexes characterized by high stability and slow reduction kinetics. Our data suggest that these stability and redox properties protect the copper(II) complexes of this TSC subclass from premature reduction-induced ligand liberation allowing the interaction of the copper(II) complexes with intracellular targets such as the ER-resident PDI. In contrast, the copper complexes of TSCS such as Triapine are sensitive to rapid reduction and thus ligand liberation inside the cancer cells, which are efficiently protected from the generated superoxide by the upregulated enzyme superoxide dismutase (SOD) in cell culture as well as in a tumor model in vivo. 


\section{Results}

\section{Anticancer activity and paraptosis-inducing potential of the TSC panel}

As a first step, the in vitro anticancer activity of the selected $\alpha-N$-pyridyl TSCs (see Table 1 for their chemical formulae) and their preformed (i.e. in situ generated) copper(II) complexes (in a 1:1 metal-to-ligand ratio) was measured in human colon adenocarcinoma SW480 and uterine sarcoma MES-SA cells as well as the multidrug-resistant subline MESSA/Dx5. SW480 cells were investigated by conventional MTT assay, while the fluorescently labelled MES-SA and MES-SA/Dx5 cells were tested in co-culture using an automated system (Figure $1 \mathrm{~A}$ and B, Table 1 and 2 as well as Suppl. Table 1 - 4) (55). In accordance to previous reports $(27-29,47,52)$, following 72 or $144 \mathrm{~h}$ incubation, the three terminally dimethylated compounds pyridine-2-carbaldehyde thiosemicarbazone (PTSC), $\mathrm{Me}_{2} \mathrm{NNMe}_{2}$, Dp44mT and the disubstituted derivative DpC showed distinctly higher anticancer activities than the other compounds (2-formylpyridine thiosemicarbazone (FTSC), Triapine, $\mathrm{H}_{2} \mathrm{NNHMe}, \mathrm{H}_{2} \mathrm{NNMe}_{2}, \mathrm{MeHNNMe}_{2}, \mathrm{Me}_{2} \mathrm{NNH}_{2}, \mathrm{Me}_{2} \mathrm{NNHMe}$ ). This was especially pronounced in the MES-SA/Dx5 cell model, reflecting the collateral sensitivity of the P-gpoverexpressing cells to this subtype of TSCs (Table 1 and 2, Figure 1B).

In order to gain more insight into the time dependency of these effects, the activity of the compounds was also assessed after 3 and $24 \mathrm{~h}$. None of the metal-free ligands exhibited relevant anticancer activity after $3 \mathrm{~h}$ resulting in $\mathrm{IC}_{50}$ values above the highest tested concentration of $25 \mu \mathrm{M}$. With the exception of PTSC, Dp44mT and DpC, the compounds did not decrease viability following a $24 \mathrm{~h}$-long incubation with the tested cancer cells. Interestingly, in contrast to the later time points (Figure 1B), collateral sensitivity of MESSA/Dx5 cells was not observed at $24 \mathrm{~h}$ (Suppl. Table 2 and 3), indicating that the collateral sensitivity might be based on enhanced cell cycle arrest rather than enhanced apoptosis. The anticancer activity of copper(II) complexes was slightly different (Table 1 and 2 as well as Suppl. Table 1 - 4). Several complexes were already active after a relatively short incubation time $(24 \mathrm{~h}$ ) in SW480 cells (Suppl. Table 1 - 3), showing the same activity pattern as observed in the $72 \mathrm{~h}$ experiment (Table 1). However, after $72 \mathrm{~h} \mathrm{IC_{50 }}$ values of all tested copper complexes were in a similar range as the respective metal-free ligands (Figure $1 \mathrm{~A}$, Table 1), with the exception of $\mathrm{Me}_{2} \mathrm{NNHMe}$, which was significantly more active 
as a copper(II) complex. Thus, the long-germ anticancer activity of the copper complexes of the nanomolar-active TSCs was similar to that of the respective metal-free ligand.

In order to investigate the paraptosis-inducing potential of the compounds, perinuclear vesicle formation was investigated by microscopy after drug treatment (Figure 1C). In agreement with previous results (13), $\mathrm{Me}_{2} \mathrm{NNMe}_{2}, \mathrm{Dp} 44 \mathrm{mT}$ and $\mathrm{DpC}$ induced high levels of vacuolization in SW480 cells already at $0.1 \mu \mathrm{M}$ drug concentrations (Figure $1 \mathrm{C}$ and D). In addition, also incubation with the terminally dimethylated PTSC, $\mathrm{H}_{2} \mathrm{NNMe}_{2}$ and $\mathrm{MeHNNMe}_{2}$ likewise induced paraptosis (however, vacuolization at $0.1 \mu \mathrm{M}$ was observed only in case of PTSC, while for the other two derivatives, the effect was visible only at 1 $\mu \mathrm{M}$, reflecting their higher $\mathrm{IC}_{50}$ values). Similar results were obtained in MES-SA cells (Suppl. Figure 2).

\section{Proton dissociation processes and $\mathrm{p} K_{\mathrm{a}}$ values of the investigated TSCs}

As there is a distinct structure-activity relationship in our TSCs panel, subsequently, we characterized whether these effects are reflected by differences in their chemical properties. While for Triapine and some derivatives several reports on proton dissociation processes are available (5-7), for most of the compounds in this study this parameter has not been characterized so far (especially not in pure aqueous solution). First, $\mathrm{p} K_{\mathrm{a}}$ values were determined by UV-visible (UV-vis) spectrophotometric titrations in pure water at compound concentrations of $10-50 \mu \mathrm{M}$. In case of $\mathrm{DpC}$, addition of some dimethyl sulfoxide (DMSO) was necessary and the $\mathrm{p} K_{\mathrm{a}}$ values of $\mathrm{DpC}$ in pure water were estimated by extrapolation (Table 3; Suppl. Figure 3A). For all compounds, the measured UV-vis spectra revealed characteristic changes upon increasing $\mathrm{pH}$, as it is depicted exemplarily for $\mathrm{Me}_{2} \mathrm{NNMe}_{2}$ in Figure 2A. The $\mathrm{pH}$-dependence of the absorbance values always showed two well-separated deprotonation steps: one at $\mathrm{pH}$ 2.5-6.0 and one at 8.0-11.5. Therefore, two $\mathrm{p} K_{\mathrm{a}}$ values could be determined (Table 3). The $\lambda_{\max }$ and $\varepsilon$ values of the ligand species in the different protonation states are collected in Suppl. Table 5. The calculated individual spectra (e.g. for $\mathrm{Me}_{2} \mathrm{NNMe}_{2}$ in Suppl. Figure 3B) represent significant differences between the molar absorptivities of the various ligand species (Suppl. Table 5). Notably, the $p K_{a}$ of the second pyridyl moiety in Dp44mT and DpC could not be determined under the applied conditions due to its fairly acidic character. Analysis of the $\mathrm{p} K_{\mathrm{a}}$ values revealed that $\mathrm{N}$ terminal dimethylation results in slightly higher $\mathrm{p} K_{\mathrm{a}}\left(\mathrm{H}_{2} \mathrm{~L}^{+}\right)$and lower $\mathrm{p} K_{\mathrm{a}}(\mathrm{HL})$ (Triapine vs. 
$\mathrm{H}_{2} \mathrm{NNMe}_{2}$ or FTSC vs. PTSC etc.), whereas dimethylation of the pyridine amine increases slightly both $\mathrm{p} K_{\mathrm{a}}$ values (Triapine $v s$. $\mathrm{Me}_{2} \mathrm{NNH}_{2}$ ). At the same time monomethylations have only a minor influence. The dipyridyl derivatives Dp44mT, DpC as well as FTSC and PTSC possess decreased $\mathrm{pK}_{\mathrm{a}} \mathrm{H}_{2} \mathrm{~L}^{+}$by almost one order of magnitude, but no clear trend was evident for $\mathrm{p} K_{\mathrm{a}} \mathrm{HL}$. In general, not only the electron-donating/withdrawing properties of the substituents should be considered to explain differences in $p K_{a}$ values, but also the ability of the derivatives to be stabilized by mesomeric/resonance effects (e.g. the thione/thiol equilibrium). As apparent from the determined $\mathrm{p} K_{\mathrm{a}}$ values all TSCS investigated in this study are charge neutral (in $\mathrm{HL}$ form) at physiological pH.

High copper(II) complex solution stability is an important parameter for anticancer activity

Having characterized the (de)protonation behavior of our TSCs, we evaluated the stability of the respective copper complexes in aqueous solution. Based on our previous findings $(5,6)$, we assumed that some of the studied $\alpha-N$-pyridyl TSCs (Triapine, FTSC, PTSC, $\mathrm{H}_{2} \mathrm{NNMe}_{2}$ ) form very stable [CuL] ${ }^{+}$complexes in a wide $\mathrm{pH}$ range. At lower $\mathrm{pH}$, the balance shifts to $[\mathrm{CuLH}]^{2+}$ complexes, containing the protonated ligand. In contrast, a mixed hydroxido complex $[\mathrm{CuL}(\mathrm{OH})]$ is prevalent in the basic $\mathrm{pH}$ range, while at ligand excess further species (e.g. $\left[\mathrm{CuL}_{2}\right],\left[\mathrm{Cu}_{2} \mathrm{~L}_{3}\right]^{+}$) can be found (6).

Equimolar aqueous solutions of the metal ion and the respective ligands (10 or $25 \mu \mathrm{M}$ concentration) were titrated and the deprotonation processes of the complexes were followed spectrophotometrically (Figure $2 \mathrm{~B}$ for $\mathrm{Cu}-\mathrm{Me}_{2} \mathrm{NNH}_{2}$ ). Deconvolution of the spectra resulted in the $\mathrm{p} K_{\mathrm{a}}$ values of the copper(II) complexes and their individual absorbance spectra (Suppl. Table 6, Suppl. Figure 3C). All $p K_{\mathrm{a}}$ values were in the range of 2.1-2.6 (for $[\mathrm{CuLH}]^{2+}$ ) and 8.1-8.8 (for $[\mathrm{CuL}]^{+}$) and thus well comparable to reported data of FTSC (with 1\% DMSO) (1). In general, the $\mathrm{p} K_{\mathrm{a}}$ value of $[\mathrm{CuLH}]^{2+}$ was by 7.2-8.6 orders of magnitude lower compared to that of the metal-free $\mathrm{HL}$ form, revealing that displacement of the dissociable proton in the complex is mediated by the metal ion coordination. As the formation of the complex $[\mathrm{CuL}]^{+}$is predominant in a wide $\mathrm{pH}$ range (4-6.5) (Figure $2 \mathrm{C}$ for $\mathrm{Cu}$-Triapine) and assumed to be quantitative due to the high solution stability, apparent (conditional) formation constants $\left(b^{\prime}\right)$ for this type of complexes were subsequently determined by competition experiments with EDTA (24) (Figure 2D for 1:1 Cu-Me $\mathrm{NNHMe}_{2}$ 
and Suppl. Figure 3D). Since the displacement was found to be relatively slow, $1-2 \mathrm{~h}$ equilibration time was applied for this reaction (the reverse experiment using CU-EDTA + FTSC resulted in the same endpoint; see Suppl. Figure 4). Increasing amounts of EDTA resulted in decreasing absorbance at the wavelength characteristic for the $\mathrm{S} \rightarrow \mathrm{Cu}$ charge transfer band (e.g. $422 \mathrm{~nm}$ in case of $\mathrm{Me}_{2} \mathrm{NNHMe}$ in Figure 2D). Taken into account the conditional stability constants determined (Suppl. Table 6) as well as the proton dissociation constants of the ligands (Table 3 ), the overall stability constants $(6)$ of the complexes $[\mathrm{CuL}]^{+}$were calculated (Table 3). Furthermore, also the $b$ values of the other two types of complexes $[\mathrm{CuLH}]^{2+}$ and $[\mathrm{CuL}(\mathrm{OH})]$ were computed (Table 3 ) using the $\mathrm{p} K_{\mathrm{a}}$ of $[\mathrm{CuLH}]^{2+}$ and $[\mathrm{CuL}]^{+}$(Suppl. Table 6). Based on these data, it can be concluded that at physiological $\mathrm{pH},[\mathrm{CuL}]^{+}$is the most predominant species, accompanied by a smaller fraction (3.9-16.3\%) of [CuL(OH)] (Table 3, Figure 2C).

Since a direct comparison of the $\log \beta[\mathrm{CuL}]^{+}$constants is not adequate due to the different basicity of the ligands, $\mathrm{pCu}(-\log [\mathrm{Cu}(\mathrm{II})])$ values were calculated in order to compare the copper(II)-binding ability of the studied TSCs at $\mathrm{pH} 7.4$ (a higher $\mathrm{pCu}$ value indicates a stronger metal ion-binding ability of the ligand) (Table 3). The calculated $\mathrm{pCu}$ values revealed that dimethylation at both the terminal and the pyridine amino group increased complex stability. On the contrary, the effect of monomethylation on the copper(II)binding ability was minor at both positions. Undoubtedly, the four compounds with activity in the nanomolar range form copper(II) complexes with the highest stability, followed by the two trimethylated compounds $\mathrm{MeHNNMe}_{2}$ and $\mathrm{Me}_{2} \mathrm{NNHMe}$ and all other derivatives (Table 3).

To evaluate the effect of copper complex stability on the biological activity, the pCu and 72 $\mathrm{h} \mathrm{plC}_{50}$ values of either the ligands or their in situ generated copper complexes were correlated. These analyses revealed that the ligands with high $\mathrm{plC}_{50}$ values possess a higher copper(II)-binding ability (indicated by higher pCu values) and the correlation is even more pronounced for the $\mathrm{pIC}_{50}$ values of the copper(II) complexes (Figure 2E and Suppl. Figure 4). Accordingly, the higher copper complex stability was also associated with higher activity in the multidrug-resistant cells after long-term incubations (Figure 2F) and paraptosis induction (Figure $2 \mathrm{G}$ ), indicating an important role of the copper(II) complex in these TSC-induced effects. 


\section{Reduced reduction rate of copper(II) complex has a strong impact on TSC activity}

In addition to the stability of the formed copper(II) complexes, also their redox properties may have an impact on their biological activities. In order to investigate, whether there are differences in the reduction rates of our TSC panel, the redox reactions of the in-situ generated copper(II) complexes with two physiological reducing agents, namely ascorbic acid (AA) and L-glutathione (GSH), were studied. Reduction of the copper(II) complexes was followed spectrophotometrically in aqueous solution at $\mathrm{pH} 7.4$ under anaerobic conditions.

In good agreement with the literature (11), no time-dependent spectral changes were observed in the case of AA which suggests that these metal complexes cannot be reduced by AA under the applied conditions (see Suppl. Figure 5). This could be explained by the relatively weak reducing power of ascorbate (formal potential at $\mathrm{pH} 7.4$ : $+0.05 \mathrm{~V}$ for dehydro-L-ascorbate/AA) (15). In contrast, the stronger reducing agent GSH (formal potential at $\mathrm{pH}$ 7.4: $-0.26 \mathrm{~V}$ for GSSG/GSH (45) reduced all studied copper(II) TSC complexes, although with different rates (Figure $3 \mathrm{~A}$ and $\mathrm{B}$ ).

The first recorded spectrum after mixing the reactants showed a small shift of the $\lambda_{\max }$ value (e.g. $448 \rightarrow 452 \mathrm{~nm}$, as shown for Cu-MeHNNMe 2 in Figure 3A) most probably due to the formation of a mixed ligand complex with GSH, as it is reported for various TSC complexes $(22,44)$. This shift was followed by a significant decrease of the absorbance at this $\lambda_{\max }$, while the absorbance value at the $\lambda_{\max }$ of the free ligand ( $\sim 382 \mathrm{~nm}$ ) increased, probably as a result of the decomposition of the generated unstable copper(I) complex. Noteworthy, oxygenizing (bubbling $\mathrm{O}_{2}$ into) the solution regenerated the original copper(II) complexes, confirming the reversibility of the redox process (data not shown). The other studied TSCs behaved similarly. However, significant differences were observed regarding the reduction rates of the respective complexes (Figure 3B). In order to obtain comparable data, the recorded absorbance/time curves were further analyzed at the $\lambda_{\max }$ of the complexes. The calculated $k_{\mathrm{obs}}$, half-lives $\left(t_{1 / 2}\right)$ and percentage of non-reduced complex after $1 \mathrm{~h}$ in the presence of 50 equiv. (1.25 mM) of GSH are collected in Table 4. For selected complexes (Triapine, PTSC), kinetic runs were additionally performed at other equivalents of GSH, and $k_{\text {obs }}$ were found to be very sensitive to the concentration of the reducing agent, namely slower reaction rates with decreasing excess of GSH were 
observed (data not shown). In accordance to the reports from Santoro et al. (44) under the applied conditions, the reduction of the copper(II) complexes was incomplete, especially with nanomolar-active compounds (see plateau in Figure 3B and \% non-reduced copper(II) complex after $1 \mathrm{~h}$ in Table 4). Interestingly, the remaining fraction of non-reduced copper(II) complex after $1 \mathrm{~h}$ (Table 4) showed a strong correlation with the $\mathrm{pCu}$ value and, therefore, with the solution stability of the copper(II) complexes (Figure 3C). These data demonstrate that the copper(II) complexes of $\alpha$-N-pyridyl TSC ligands bearing higher solution stability can only be reduced by GSH in a slower and much less effective way. When these reduction rates were subsequently correlated with the anticancer activity (after $72 \mathrm{~h}$ ), it became apparent that a slower reduction rate is associated with higher anticancer activity (Figure 3D and Suppl. Figure 6A) and paraptosis-inducing potential (Figure 3E and Suppl. Figure 6B) of the metal-free ligands as well as the copper complexes. Overall, these results are surprising, as so far it has been assumed that the anticancer activity of copper TSC complexes is mainly based on intracellular redox activity, either by the copper(II) TSC itself or by the copper release from the complex in the cell $(22,44)$.

\section{Copper(II) complex stability influences redox behavior of TSCs under cell-free conditions}

It is widely accepted in the literature $(22,27,38,44)$, that reduction of copper(II) complexes to copper(I) and their subsequent re-oxidation under aerobic conditions, results in the generation of superoxide radicals and thus redox stress in treated cells. In order to compare the obtained reduction rates of the copper(II) complexes by GSH to their superoxide production potential, formation of cell-free superoxide was measured spectrophotometrically using the nitroblue tetrazolium (NBT) assay. In line with the activation by reduction theory for this compound class (16), without the addition of a reducing agent, none of the tested TSCs (neither as metal-free ligand nor as copper(II) complex) induced any positive signal (data not shown). In contrast, as expected when the GSH precursor and reducing agent $N$-acetyl cysteine (NAC) was added to the copper(II) complexes, superoxide generation (up to 1.6-fold compared to the control) was detected (Figure 3F). In agreement with the above shown results, distinct differences between the individual ligands were observed. Thus, indeed copper(II) complexes with a higher stability and slower reduction rate produced also less cell-free superoxide (Figure 3G and Suppl. Figure 7). In contrast, copper ions, which under certain conditions have been reported to 
induce ROS on their own $(10,41)$, did not result in positive measurable NBT signals (at 5 $\mu \mathrm{M})$ neither alone nor in combination with NAC (data not shown). Consequently, these data indicate that despite the widely accepted hypothesis that the anticancer activity of copper(II) complexes is based on (intracellular) reduction-induced ROS (superoxide) formation, in our hands especially the TSC complexes showing reduced redox activity are characterized by distinctly enhanced cytotoxicity.

\section{Stimulation of antioxidant enzymes and stress-response genes in TSC-treated cells}

In order to investigate, whether we can also detect superoxide production upon drug treatment in living tumor cells, the dihydroethidium (DHE) assay was used at conditions similar to the cell-free assay. Comparably to the results of the cell-free experiments, neither the ligands nor copper ions $(5 \mu \mathrm{M})$ alone did significantly increase the fluorescence signals (data not shown). Unexpectedly, for the copper(II) complexes a different picture emerged compared to the cell-free experiments, as no significant increase in superoxide levels could be detected neither in presence nor in absence of NAC (Figure 4A). Hypothesizing that cancer cells efficiently protect themselves from TSC-induced redox stress by upregulation of antioxidant response signaling, we used our previously published (13) whole genome gene expression data of Triapine- and $\mathrm{Me}_{2} \mathrm{NNMe}_{2}$-treated SW480 cells. In these experiments cells were treated either with Triapine $(1 \mu \mathrm{M}), \mathrm{Me}_{2} \mathrm{NNMe}_{2}(0.1$ and $1 \mu \mathrm{M}$ ) or solvent for $15 \mathrm{~h}$ and mRNA levels were analyzed for drug-induced changes in gene transcription. When looking for altered gene sets associated with response to oxidative stress (e.g. "regulation of response to oxidative stress") by gene set enrichment analysis (GSEA), no significant gene set enrichment was detected (lowest FDR values: 0.10 for $\mathrm{Me}_{2} \mathrm{NNMe}_{2}$ and 0.35 for Triapine (Suppl. Figure 8)). However, when looking at individual genes, we found upregulation of the superoxide scavenger enzymes SOD2 and SOD3, but not SOD 1 upon Triapine treatment (Figure $4 B$ ). In contrast, in $\mathrm{Me}_{2} \mathrm{NNMe}_{2}-$ treated cells no comparable upregulation was observed for SOD2 (at IC 50 concentrations) and SOD3 (Figure 4B).

For confirmation at the protein level, Western blot analysis of SOD2 with lysates from cells treated with our TSC panel were performed. Indeed, SOD2 was upregulated after treatment with Triapine and all other micromolar-active TSCs, while none of the compounds with activity in the nanomolar concentration range induced SOD2 expression 
(Figure $4 C$ and D). To test whether SOD2 was also upregulated by Triapine treatment in tumor cells in vivo, CT-26 colon carcinoma-bearing mice were treated orally with either solvent or $10 \mathrm{mg} / \mathrm{kg}$ Triapine. As shown in Supp. Figure 10, Triapine had significant anticancer activity and was well tolerated in this setting. On the last day of treatment (day 15), the tumors were collected and immunohistochemically stained for SOD2. In accordance with the array data as well as the Western blot analysis, also tumors from Triapine-treated animals showed strong stimulation of SOD2 expression compared to the solvent control (Figure 4E).

Overall, the significant upregulation of SOD is in line with the hypothesis of efficient degradation of TSC-induced ROS and might explain the discrepancy of superoxide production between the cell-free and cell culture experiments observed above. Despite its much higher cytotoxicity, the SOD stimulation was weaker in case of $\mathrm{Me}_{2} \mathrm{NNMe}_{2}$ and the nanomolar-active TSCs, indicating that (in contrast to Triapine) at drug doses in the $\mathrm{IC}_{50}$ range no significant generation of superoxide occurs in the treated cells with these compounds. Consequently, it can be hypothesized that due to the higher resistance of the copper(II) complexes towards reduction, the compounds are less efficient in ROS production inside of cells.

Based on the assumed importance of metal chelation in the mode of action of TSCs, we also investigated changes in pathways regarding metal homeostasis in our arrays. Interestingly, we found only one significantly changed gene set, namely upregulation of genes involved in "response to zinc ions" after treatment with $\mathrm{Me}_{2} \mathrm{NNMe}_{2}$ (Figure 4F). This is of interest, as a closer look on this gene set revealed that, this gene set mainly contains metallothioneins (which are cysteine-rich, low molecular weight proteins being responsible also for copper homeostasis) as well as the copper transporters ATP7A and ATP7B (Figure 4G).

\section{High copper complex stability is important for PDI inhibition potential}

In a previous study, we showed that $\mathrm{Me}_{2} \mathrm{NNMe}_{2}$ induces paraptosis by inhibition of the ERresident PDI and consequent disruption of the ER thiol redox homeostasis (13). Therefore, the here studied copper-TSC complexes were tested for their potential to inhibit this enzyme. In line with our previous report (13), copper in form of a simple salt was already able to inhibit the PDI enzymes to some extent. This inhibition distinctly increased when 
copper was complexed by $\mathrm{Me}_{2} \mathrm{NNMe}_{2}$ or other TSCs with terminal dimethylation/disubstitution (Figure 5A). Interestingly, the inhibition followed an "all-or-nothing" pattern with complexes showing either the same weak inhibition as copper ions alone or strong PDI-disrupting ability comparable to the $\mathrm{Me}_{2} \mathrm{NNMe}_{2}$ complex. Dividing the compounds in these two categories, it can be clearly seen that PDI inhibition is associated with higher complex stability, higher anticancer activity and enhanced vesicle formation (Figure 5B and Suppl. Figure 11). Thus, although inhibition of the PDI is probably not the only target of the nanomolar-active TSCs (other targets may include the ribonucleotide reductase (RR) inhibition) $(29,58)$, this indicates that there is a link between redox properties and copper complex stability with PDI inhibition and paraptosis induction, which needs to be further investigated in future studies.

\section{Discussion}

TSCs have long been known for their anticancer activity and their metal-chelating abilities $(16,23)$. In case of the currently in phase III clinically investigated derivative Triapine, especially an interaction with the iron homeostasis was suggested based on its strong inhibition of the iron-containing ribonucleotide reductase and the occurrence of methemoglobinemia as the main adverse effect in patients (16). With the aim to develop TSCs with improved efficiency, derivatives with activity in the nanomolar IC 50 range (such as $\mathrm{DpC}, \mathrm{Dp} 44 \mathrm{mT}$ and $\mathrm{Me}_{2} \mathrm{NNMe}_{2}$ ) came into the focus of interest during the last decade of which DpC also recently entered clinical trials $(2,20,28,29)$. An increasing body of evidence indicates that these drugs have additional modes of action that are responsible for their increased cytotoxicity. The particularities of nanomolar-active TSC are indicated by the induction of 1) a specific form of ER stress associated with disruption of the ER thiol redox homeostasis and inhibition of the ER protein PDI $(13,14,39,53), 2)$ a just recently discovered form of programmed cell death called paraptosis (13), and 3) increased activity in some multidrug-resistant cancer cells $(9,40,46)$. Significantly, for all of these effects, the interactions with (intracellular) copper pools leading to formation of redox-active copper complexes were suggested to be crucial $(16,19,34)$. Thus, it was proposed that copper complexes induce ROS (superoxide) by redox reaction with intracellular reductants, a mechanism also referred to as "activation by reduction" $(11,34,36,44,49)$. Accordingly, a strong synergism between the metal-free ligand and free copper salts has been repeatedly 
reported for nanomolar-active TSCs $(19,28,49)$. However, the experiments supporting the ROS model were often performed either with preformed copper(II) complexes $(11,34)$ or by preincubation of the ligands with high levels of extracellular copper $(28,36,49)$. In contrast, in many cases, incubation with the metal-free ligands alone did not induce global ROS detectable for example by the DCF-DA stain $(13,28,34)$. Thus, it might be hypothesized that, although there are indications that copper plays an important role in the mode of action of nanomolar-active TSCs, under physiological conditions, this might not be due to reductant-induced global redox stress production. However, localized and slower nonROS-producing redox reactions (e.g. formation of disulfide bridges) might still be involved in their activity.

The aim of this study was to further investigate the role of copper in the activity of nanomolar-active TSCs in comparison to micromolar-active derivatives such as Triapine. To this end, a selected panel of structurally related $\alpha-N$-heterocyclic TSCs and their respective copper(II) complexes was investigated with regard to solution stability, cell-free as well as intracellular redox properties, toxicity against sensitive and MDR cancer cell lines and paraptosis-inducting potential. We show that the activity of the compounds has a strong correlation with these properties, confirming the relevance of their interaction with copper ions (Figure 5C).

To analyze the interaction of the compounds with copper in more detail, we compared the anticancer activity of the preformed copper complexes with that of the metal-free ligands, together with their potential to induce collateral sensitivity in a P-gp-overexpressing cell model. Thereby, crucial differences were observed between short- and long-term drug incubation. While short incubation times ( 3 and $24 \mathrm{~h}$ ) resulted in higher anticancer activity for especially nanomolar-active TSC copper(II) complexes compared to metal-free ligands, after longer incubation times (72 and $144 \mathrm{~h}$ ), mostly no enhanced efficiency of the copper complexes was observed. The increased activity is in line with the literature showing (mainly for the nanomolar-active compounds) an enhanced activity of the metal-free ligands when co-applied with an excess of simple copper salts $(19,28,49)$ or of preformed 1:1 or 1:2 copper(II):Dp44mT complexes compared to the metal-free ligand (20). An exception to the increased activity were copper(II) complexes of Triapine, $\mathrm{H}_{2} \mathrm{NNHMe}$ and $\mathrm{H}_{2} \mathrm{NNMe}_{2}$, which showed no activity after short-time and even lower activity compared to 
the metal-free ligand after long-term incubation. This may be explained by a less efficient absorption and cellular uptake of the charged $[\mathrm{CuL}]^{+}$species compared to the neutral $\mathrm{HL}$ ligand which are the predominating forms in solution at physiological $\mathrm{pH}$ based on our solution speciation studies in all cases. After longer incubation times, the differences in activity between the copper(II) complexes and the respective metal-free ligands disappeared which could be explained by the hypothesis of different kinetics of the underlying cell killing mechanisms as described by Ishiguro et al. (19). Thus, while the rapid cell killing mechanism is conducted by extracellular TSC copper complexes and characterized by redox reactions (27), the slow activity is redox-independent and depends more on the ligand and/or intracellular copper complexation. In this regard, MES-SA/Dx5 cells were found to be more resistant against the rapid cell killing mechanism of both the metal-free ligands and preformed complexes compared to the parental MES-SA cells (seen in the $24 \mathrm{~h} \mathrm{IC} 50$ values), while they were (slightly) more sensitive to the long-term activity of most copper complexes compared to the respective ligands. The exception were complexes of TSCs such as Triapine, $\mathrm{H}_{2} \mathrm{NNMeH}$ and $\mathrm{H}_{2} \mathrm{NNMe}_{2}$, with lower activity compared to metal-free ligands, that also did not exhibit increased activity in MES-SA/Dx5 cells as either ligand or complex. In fact, collateral sensitivity of MES-SA/Dx5 cells correlated with higher copper(II) complex stability, which further points to the importance of copper chelation for nanomolar TSC activity. This is in good agreement with previous studies, as also P-gp-overexpressing and Triapine-resistant SW480 or colchicine-resistant KB-3-1 cells showed no cross-resistance against terminally or pyridine amino di-substituted (especially nanomolar) TSCs after long-term incubation $(28,52)$.

It is important to note that the copper(II) complexes of the studied TSC ligands have the same composition $\left([\mathrm{CuL}]^{+}\right)$with the same coordination mode $\left(\mathrm{N}_{\text {pyridyl }}, \mathrm{N}, \mathrm{S}^{-}\right)\left(\mathrm{H}_{2} \mathrm{O}\right)$ at $\mathrm{pH} 7.4$ in aqueous solution. However, significant differences were seen regarding their stability. Namely, the nanomolar-active TSCs form complexes of significantly higher stability with this metal ion compared to the micromolar compounds. On the other hand, the copper(II) complexes of the nanomolar TSCs could be reduced by GSH in a much slower redox reaction. When we investigated the role of redox activity, opposing to the current theory of activation by reduction $(16,20,27)$, nanomolar-active TSCs were characterized by copper(II) complexes with higher stability and less efficient reduction by reducing agents. 
This observation is in line with other studies such as from Garcia-Tojal et al., and from Santoro et al. who both found slower reduction by GSH in the case of the copper(II) complex of Dp44mT, as compared to the copper(II) complexes of Triapine and FTSC/PTSC $(11,44)$. Moreover, for both Triapine as well as FTSC, reduction of the copper(II) complex resulted in efficient binding of the copper(I) ion to GSH leaving a metal-free ligand able to interact with other metal ions such as iron or zinc (44). In agreement with a slower reduction, also cell-free superoxide production (which results from re-oxidation of the copper(I) complex) was lower with these complexes. Interestingly, the confirmation of these data in living cells turned out to be difficult. Thus, at physiologically relevant conditions, none of the TSC complexes increased DHE fluorescence (indicating intracellular superoxide) neither in presence of a thiol-containing reducing agent (NAC) nor in its absence. Consequently, we hypothesized that cells rapidly adapt to redox stress and efficiently degrade the drug-generated superoxide.

In line with a higher, cell-free superoxide production of Triapine and its closest (micromolar-active) derivatives, upregulation of the superoxide-degrading enzymes SOD2/3 on mRNA and protein levels was identified as a possible protection mechanism. This is of interest as comparable upregulation and increased activity of SOD enzymes was also reported and shown to protect against treatment with TSC copper complexes by other groups $(11,48,51)$. This stimulation of SODs only in case of micromolar-active TSCs led us to the theory that in case of Triapine and its close derivatives, the rather fast (intracellular) reduction leads to rapid dissociation of the copper complex and thus liberation of the metal-free ligands (which is also in good agreement with the very recently published data of Santoro et al. (44)). Consequently, metal-free (or iron-/zinc-bound) Triapine could be the main species occurring inside the cell, playing a primary role in anticancer activity. In contrast, as copper(II) complexes of nanomolar-active TSCs are much slower in their reduction and thus more stable, the copper(II) complex is able to reach intracellular targets such as the ER-resident protein PDI (Figure 5D). In line with this hypothesis, paraptosis induction, measured by vacuole formation, was most pronounced with the nanomolar-active TSCs. This increase in paraptosis induction also correlated with the solution stability of their copper complexes as well as a slower reduction rate. In addition, 
also PDI inhibition by the TSC complexes highly correlated with copper complex stability and vacuole formation.

In line with a more pronounced role of copper in the anticancer activity of nanomolaractive TSCs, our array analysis revealed that $\mathrm{Me}_{2} \mathrm{NNMe}_{2}$ induces upregulation of metallothioneins, which strongly bind diverse metal ions including copper(I). Noteworthy, metallothioneins also contain multiple thiol groups, and thus take part in the cellular thiol redox homeostasis (43), which seems to be disrupted by the nanomolar-active TSC copper complexes (13). Interestingly, it has been suggested by Santoro et al. that metallothioneins play a crucial role in the removal of the reduced copper(I) from Triapine and FTSC after reduction, while in case of Dp44mT the interaction of zinc-loaded metallothioneins with the copper(I)-TSC-GSH complex resulted in zinc transmetalation (44). In accordance, also our data indicate that there might be an interaction with metallothioneins also in the cytosol (but not in the ER) of living cells after treatment with the metal-free TSC ligand. The exact nature of this interaction definitely warrants further investigations.

\section{Innovation (100 words)}

In conclusion, the here presented work on the one hand, confirms that interaction with copper ions plays an important role in the anticancer activity of nanomolar-active TSCs. On the other hand, it also raises strong doubts on the dogma of "activation by reduction" induced redox stress via superoxide production as main executer of (metal-free applied) drug effectivity. In contrast, we propose that due to their high solution stability, copper(II) complexes of nanomolar-active TSCs are able to reach additional intracellular protein targets such as the ER-resident PDI resulting in paraptotic cell death induction and increased anticancer activity.

\section{Materials and Methods}

\section{Chemicals}

FTSC, PTSC, Triapine, $\mathrm{H}_{2} \mathrm{NNHMe}, \mathrm{H}_{2} \mathrm{NNMe}_{2}, \mathrm{MeHNNMe}_{2}, \mathrm{Me}_{2} \mathrm{NNH}_{2}, \mathrm{Me}_{2} \mathrm{NNHMe}$, $\mathrm{Me}_{2} \mathrm{NNMe}_{2}, \mathrm{FTSC}, \mathrm{MeHNNH}_{2}, \mathrm{MeHNNHMe}, \mathrm{Dp} 44 \mathrm{mT}$ and DpC were prepared as described previously $(28,29,35)$. Ethylenediaminetetraacetic acid (EDTA), $\mathrm{KCl}, \mathrm{KOH}, \mathrm{HCl}$ was obtained from Reanal (Hungary), 2-(N-morpholino)ethanesulfonic acid (MES) and 4-(2hydroxyethyl)-1-piperazineethanesulfonic acid (HEPES) was purchased from Sigma-Aldrich 
and used without further purification. Copper(II) stock solution was prepared by the dissolution of $\mathrm{CuCl}_{2}$ in water and its concentration was determined by complexometry with EDTA. For cell culture experiments TSCs were first diluted in DMSO (10 mM) after which further dilutions were performed in aqueous solutions (double distilled (dd) $\mathrm{H}_{2} \mathrm{O}$, buffer or cell culture media depending on the assay) or with which copper complexes were formed in combination with $\mathrm{CuCl}_{2}\left(10 \mathrm{mM}\right.$ in $\left.\mathrm{ddH}_{2} \mathrm{O}\right)$. Thereby, concentrations of DMSO in cell culture did not reach toxic doses. For spectrophotometric measurements, TSCs were directly diluted in $\mathrm{dd}_{2} \mathrm{O}$ at low concentrations $(255 \mu \mathrm{M})$ and dissolution was improved by ultrasound bath and adding low concentration of $\mathrm{HCl}$.

\section{Spectrophotometric titrations}

A Hewlett Packard 8452A diode array spectrophotometer was used to record the UV-Vis spectra in the interval 200-800 $\mathrm{nm}$. The path length was $1 \mathrm{~cm}$. Proton dissociation constants $\left(\mathrm{p} K_{\mathrm{a}}\right)$ of the TSC ligands, the copper(II) mono complexes and the individual spectra of the species in the various protonation states were calculated by the computer program PSEQUAD (31). Spectrophotometric titrations were performed on samples containing the ligands at $10-50 \mu \mathrm{M}$ concentration by a $\mathrm{KOH}$ solution in the presence of 0.1 $\mathrm{M} \mathrm{KCl}$ at $25.0 \pm 0.1{ }^{\circ} \mathrm{C}$ in the $\mathrm{pH}$ range from 2 to 11.9. An Orion $710 \mathrm{~A} \mathrm{pH}$-meter equipped with a Metrohm combined electrode (type 6.0234.100) and a Metrohm 665 Dosimat burette were used for the $\mathrm{pH}$-metric titrations. The electrode system was calibrated to the $\mathrm{pH}=-\log \left[\mathrm{H}^{+}\right]$scale by means of blank titrations $(\mathrm{HCl}$ vs. $\mathrm{KOH})$ according to the method suggested by Irving et al. (18). The average water ionization constant $\left(\mathrm{pK}_{\mathrm{w}}\right)$ is $13.76 \pm 0.05$ in water. Argon was also passed over the solutions during the titrations.

Due to the limited water solubility of $\mathrm{DpC} \mathrm{p} K_{\mathrm{a}}$ values of the ligand were determined in 5 and $30 \%(w / w) D M S O / H_{2} \mathrm{O}$ solvent mixture, while $\mathrm{p} K_{\mathrm{a}}$ values of the copper(II) complexes in $30 \%(w / w) D M S O / H_{2} \mathrm{O}$. The $\mathrm{pK}_{\mathrm{a}}$ values obtained at various DMSO content were plotted against the $1 / \varepsilon_{\mathrm{r}}$ values of the solvent medium, where $\varepsilon_{\mathrm{r}}$ is the relative permittivity (or dielectric constant) of the solvent medium and values for the pure aqueous solution were obtained by extrapolation. The $\varepsilon_{r}$ values are interpolated data taken from (4). Namely, the $\mathrm{pK}_{\mathrm{a}}$ values for $\mathrm{DpC}$ in pure water were extrapolated from the values obtained in the DMSO $/ \mathrm{H}_{2} \mathrm{O}$ mixtures with the slopes of the linear curves of $\mathrm{DpC}(5 \%, 30 \%)$, Triapine $(0 \%$, $30 \%)$ and $\mathrm{H}_{2} \mathrm{NNMe}_{2}(0 \%, 30 \%)$. 
The conditional stability constants $\left(\theta^{\prime}\right)$ of the copper(II) complexes were calculated at $\mathrm{pH}$ 5.90 based on the spectral changes via the displacement reaction with EDTA in the presence $50 \mathrm{mM}$ MES and $0.1 \mathrm{M} \mathrm{KCl}$ (using 1-2 $\mathrm{h}$ incubation). Data for $\mathrm{p} K_{\mathrm{a}}$ of EDTA and its $\mathrm{Cu}(\mathrm{II})$ complex taken from (8) and $\log \beta^{\prime}{ }_{5.90}=13.89$ was calculated for $[\mathrm{Cu}(\mathrm{EDTA})]^{2-}$. In the competition experiments the samples contained $25 \mu \mathrm{M}$ copper(II), $25 \mu \mathrm{M}$ ligand and the concentration of EDTA was varied in the range from 0 to $400 \mu \mathrm{M}$. It should be noted that EDTA and its copper(II) complex have negligible contribution to the measured absorbance values in the monitored wavelength range $(320-550 \mathrm{~nm})$, only [CuL] ${ }^{+}$and $\mathrm{HL}$ absorb light. In the case of $\mathrm{DpC}$ and Triapine the completion reaction was performed in $30 \%(\mathrm{w} / \mathrm{w})$ DMSO $/ \mathrm{H}_{2} \mathrm{O}$ solvent mixture. The conditional stability constants of the metal complexes $\left(B^{\prime}\right.$ (CuL)) and the individual spectra of the species were calculated by the computer program PSEQUAD (31). The overall stability constants of the $[\mathrm{CuL}]^{+}$complexes (B) were calculated from the conditional stability constants: $B[\mathrm{CuL}]^{+}=B^{\prime}[\mathrm{CuL}]^{+} \times \alpha_{H}$, where $\alpha_{H}=1+\left[\mathrm{H}^{+}\right] / K_{a}$ $(\mathrm{HL})+\left[\mathrm{H}^{+}\right]^{2} /\left(K_{a}(\mathrm{HL}) \times K_{a}\left(\mathrm{H}_{2} \mathrm{~L}^{+}\right)\right) ;\left[\mathrm{H}^{+}\right]=10^{-5.90} \mathrm{M}$. The overall stability constants of the protonated $[\mathrm{CuLH}]^{2+}$ and the mixed hydroxido $[\mathrm{CuL}(\mathrm{OH})]$ complexes were calculated as follows: $\log B[\mathrm{CuLH}]^{2+}=\log 6[\mathrm{CuL}]^{+}+\mathrm{p} K_{\mathrm{a}}[\mathrm{CuLH}]^{2+} . \log B[\mathrm{CuL}(\mathrm{OH})]=\log B[\mathrm{CuL}]^{+}-\mathrm{p} K_{\mathrm{a}}$ $[\mathrm{CuL}]^{+} . \mathrm{pCu}=-\log [\mathrm{Cu}(\mathrm{II})]$ values were calculated at $\mathrm{pH} 7.4$ using the determined stability constants.

\section{Spectrophotometric kinetic measurements}

The redox reaction of the copper(II) complexes with GSH and AA was studied at $25.0 \pm 0.1$ ${ }^{\circ} \mathrm{C}$ on Hewlett Packard 8452A diode array spectrophotometer using a special, tightly closed tandem cuvette (Hellma Tandem Cell, 238-QS). The reactants were separated until the reaction was triggered. Both isolated pockets of the cuvette were completely deoxygenated by bubbling a stream of argon for $10 \mathrm{~min}$ before mixing the reactants. Spectra were recorded before and then immediately after the mixing, and changes were followed till no further absorbance change was observed. One of the isolated pockets contained the reducing agent (GSH or AA) and its concentration was in the range of 250$2500 \mu \mathrm{M}$ and the other contained the copper(II) complex, which was prepared in situ using $25 \mu \mathrm{M}$ of the metal ion and the ligand respectively. The $\mathrm{pH}$ of all the solutions was adjusted to 7.40 by $50 \mathrm{mM}$ HEPES buffer and an ionic strength of $0.1 \mathrm{M}(\mathrm{KCl})$ was applied. 
The stock solutions of the reducing agents and the complexes were freshly prepared every day.

During the calculations the absorbance $(A)$ - time $(t)$ curves were fitted and analyzed at the $\lambda_{\max }$ of the complex. $\left(A_{0}-A_{\text {final }}\right) \times \mathrm{e}^{(-a \times t)}+A_{\text {final }}$ equation was used where $A_{0}, A_{\text {final }}$ and $a$ parameters were refined and accepted at the minimal value of the weighted sum of squared residuals (difference between the measured and calculated absorbance values) at the given wavelength. Then observed rate constants $\left(k_{\text {obs }}\right)$ of the redox reaction were obtained from the data points of the simulated absorbance-time curves as the slope of the $\ln \left(A / A_{0}\right)$ versus $t$ plots.

\section{Cell lines and culture conditions}

Human uterine sarcoma MES-SA and the doxorubicin selected MES-SA/Dx5 cells expressing mCherry and eGFP proteins, respectively, were engineered from MES-SA and MES-SA/Dx5 (ATCC; MES-SA: No. CRL-1976 ${ }^{\mathrm{TM}}$, MES-SA/Dx5: No. CRL-1977 ${ }^{\mathrm{TM}}$ ) using a lentiviral system (55). The phenotype of the resistant cells was verified using cytotoxicity assays (not shown). Prior to the experiments, MES-SA/Dx5 cells were cultured in 500 $\mathrm{nmol} / \mathrm{L}$ doxorubicin, to ensure Pgp expression. Cells were cultured in DMEM (SigmaAldrich, Hungary) supplemented with $10 \%$ fetal bovine serum, $5 \mathrm{mmol} / \mathrm{L}$ glutamine, and 50 units/ml penicillin and streptomycin (Life Technologies). Human colorectal adenocarcinoma SW480 cells (obtained from ATCC; No. CCL-228 ${ }^{\text {TM }}$ ) were cultured in MEME supplemented with $10 \%$ fetal calf serum (PAA, Austria). CT-26 murine colon carcinoma cells (CRL-2638, purchased from ATCC) were cultured in Dulbecco's modified eagle's medium (DMEM)/F12 medium (1:1 from Sigma; \#D6421) supplemented with $10 \%$ heatinactivated fetal calf serum. All cell lines were cultivated at $37{ }^{\circ} \mathrm{C}, 5 \% \mathrm{CO}_{2}$.

\section{Cell viability assay}

In the co-culture system, after trypsinization, suspensions of MES-SA mCherry and MESSA/Dx5 eGFP cells were mixed, and seeded on 384-well plates at a 2500 cells/well density (1250 cells/well per cell model) in $20 \mu \mathrm{l}$ of medium, one day prior to drug addition. Cells were then treated with a serial dilution of the drugs, so that the final volume was $60 \mu \mathrm{l}$. Liquid handling was fully automated by a Hamilton StarLet robotic pipetting workstation (Hamilton, Switzerland). Plates were incubated, and measured twice: after 72 and $144 \mathrm{~h}$ of 
drug addition. Growth inhibition of the cells was assessed based on the detection of the respective fluorescent intensities scanned from the wells by an EnSpire plate reader (eGFP: 485ex/510em; mCherry: 585ex/610em, Perkin Elmer, UK). Raw measurement files were exported, and automated data evaluation was performed by our custom program, which was written by Judit Sessler in C\#. Data was normalized to the negative (live cells, maximal fluorescence) and positive (dead cells, minimal fluorescence) controls, then growth inhibition data points (plotted against the respective concentrations) were connected with a line, and $\mathrm{IC}_{50}$ was considered as the point, at which the connecting line reached the $50 \%$ inhibition according to the $Y$ axis.

For single cell viability assay, SW480 cells were plated $\left(2 \times 10^{3}\right.$ cells/well) in 96-well plates and allowed to recover for $24 \mathrm{~h}$. Then, cells were treated with increasing concentrations of TSCs for $72 \mathrm{~h}$. Cell viability was measured by the 3-(4,5-dimethylthiazol-2-yl)-2,5diphenyltetrazolium bromide (MTT)-based vitality assay (EZ4U; Biomedica, Vienna, Austria) as published (17). GraphPad Prism software was used to calculate cell viability expressed as $\mathrm{IC}_{50}$ values calculated from full dose-response curves. For further analysis and comparison, $\mathrm{plC}_{50}$ values were used instead of $\mathrm{IC}_{50}$ values (Suppl. Figure 1). $\mathrm{pIC}_{50}$ values were calculated as the $-\log _{10}$ from $\mathrm{IC}_{50}$ values in molar.

\section{Microscopy}

Cells were seeded into a 24-well plate with $2 \times 10^{4}$ cells/well and left to recover for $24 \mathrm{~h}$. Then, cells were treated with indicated concentrations of TSC ligands. After 24 or $48 \mathrm{~h}$, microscopic phase-contrast images were taken with a Zeiss primo vert microscope with a Zeiss axio cam ERc5s camera. Percentage of vacuolated cells was counted in at least three different parts of a well.

\section{Quantification of superoxide radicals}

To examine the cell-free production of superoxide radicals, the reduction of NBT was analyzed as previously reported (27). Briefly, $0.6 \mathrm{mM}$ NBT was incubated with $5 \mu \mathrm{M}$ copper(II) complexes with or without 2 mM NAC. The experiments were performed in PBS $(\mathrm{pH}$ 7.4). The extent of NBT reduction was determined spectrophotometrically by measuring the absorbance at $560 \mathrm{~nm}$ after $45 \mathrm{~min}$ of incubation. No superoxide radicals were observed without NAC (data not shown). 


\section{Intracellular superoxide determination using DHE}

DHE (\#D7008, Sigma-Aldrich, MO, USA) was used to detect the production of intracellular superoxide. Briefly, $5 \times 10^{5}$ MES-SA cells per sample in $500 \mu \mathrm{l}$ of PBS $\left(78.1 \mathrm{mM} \mathrm{Na}{ }_{2} \mathrm{PO}_{4} \times 2\right.$ $\mathrm{H}_{2} \mathrm{O}, 14.7 \mathrm{mM} \mathrm{KH}_{2} \mathrm{PO}_{4}, 26.8 \mathrm{mM} \mathrm{KCl}, 1.37 \mathrm{M} \mathrm{NaCl}$ ) were incubated with or without $2 \mathrm{mM}$ NAC for $15 \mathrm{~min}$ at $37^{\circ} \mathrm{C}$. Then, $5 \mu \mathrm{M}$ of indicated TSC complexes were added for further 60 min. Subsequently, DHE (10 $\mu \mathrm{M})$ was added 30 min before measurement. After incubation, the mean fluorescence intensity was measured by flow cytometry using a FACSCalibur instrument (Becton Dickinson, Palo Alto, CA, USA). Antimycin A (AMA, $10 \mu \mathrm{M})$ was used as positive control.

\section{PDI reduction activity measurement}

PDI reduction activity was measured using PROTEOSTAT PDI assay kit (\#ENZ-51024, Enzo Life Sciences, Switzerland). Experiments were performed according to the manufacturer's instructions. Briefly, drugs alone or preincubated with $\mathrm{CuCl}_{2}(1: 1)$ were added to a prepared insulin PDI solution. Then, dithiothreitol (DTT) (1 mM) was added to start PDI reduction activity. After $30 \mathrm{~min}$ the reaction was stopped by the Stop reagent and the insulin precipitate was fluorescently labeled with Proteostat PDI detection reagent for 15 min. Fluorescence intensity was measured at $500 \mathrm{~nm}$ excitation and $603 \mathrm{~nm}$ emission using the spectrophotometer Tecan infinite 200Pro (Tecan Group, Männedorf, Switzerland).

\section{Protein expression}

After drug treatment, total protein lysates were prepared, $20 \mu \mathrm{g}$ per sample separated by SDS-PAGE and transferred onto a polyvinylidene difluoride membrane for Western blotting as described previously (17). The following antibodies were used: Cell Signaling Technology (MA, USA): SOD2 (\#13141), GAPDH (\#5174). Primary antibodies were used 1:1000. Secondary anti-rabbit (\#7074) horseradish peroxidase-labeled antibodies from Cell Signaling Technologies were used in working dilutions of 1:10 000.

\section{Total-RNA isolation and whole genome gene expression array}

Total RNA from SW480 cells (either untreated or treated (0.1 or $1 \mu \mathrm{M}$ for $15 \mathrm{~h}$ )) was isolated using RNeasy Mini kit (\#74106, Quiagen, Germany) following the manufacturer's instruction. Transcriptional profiles of cells were determined performing a $4 \times 44 \mathrm{~K}$ whole genome oligonucleotide gene expression array (Agilent, California, US) as described 
previously (32). Normalization was performed in R using the Bioconductor (version 3.7) package "limma" if not otherwise indicated (42). Whole genome gene expression array and gene set enrichment analysis (GSEA) were performed as previously described (13).

\section{Animal experiments}

Six- to eight-week-old BALB/c mice were purchased from Janvier (France). The animals were kept in a pathogen-free environment and every procedure was done in a laminar airflow cabinet. Experiments were done according to the regulations of the Ethics Committee for the Care and Use of Laboratory Animals at the Medical University Vienna (proposal number BMWF-66.009/0081-WF/V/3b/2015), the U.S. Public Health Service Policy on Human Care and Use of Laboratory Animals as well as the United Kingdom Coordinating Committee on Cancer Prevention Research's Guidelines for the Welfare of Animals in Experimental Neoplasia. To ensure animal welfare throughout the experiment, the body weight of the mice was assessed once a day. At weight loss exceeding $10 \%$ (in less than two days) or occurrence of ascites, animals were sacrificed by cervical dislocation.

\section{In vivo analysis of SOD2 expression}

CT-26 cells $\left(5 \times 10^{5}\right.$ cells in $50 \mu$ l) were injected subcutaneously into the right flank of female Balb/c mice. Starting on day 4 , Triapine $(10 \mathrm{mg} / \mathrm{kg}$ in $10 \% \mathrm{DMSO})$ or solvent treatment was given orally for 5 consecutive days a week for two weeks. Animals were sacrificed on indicated days per cervical dislocation and tumor tissue was isolated and fixed in $4 \%$ paraformaldehyde (Carl Roth, \#P087.3) for 24 h. Tumor tissue was paraffin-embedded with the KOS machine (Milestone) and sliced in $4 \mu \mathrm{m}$ thick sections. For SOD2 staining, sections were incubated with a SOD2-specific antibody (1:1000, Cell Signaling, \#13141) in a humid chamber for $1 \mathrm{~h}$ at room temperature after antigen retrieval by boiling for $30 \mathrm{~min}$ in $10 \mathrm{mM}$ citrate buffer (pH 6.0, DAKO; \#S1699),. Antibody binding was detected using the UltraVision LP detection system according to the manufacturer's instructions (Thermo Fisher Scientific Inc.; \#TL-125-HL). Color was developed using 3,3'-diaminobenzidine (Dako; \#K3468), followed by a nuclear counterstain with hematoxylin. Stained tissue slides were scanned and analyzed using Definiens Software. 


\section{Correlation analysis}

Correlations were performed in the GraphPad Prism 8 software. $\mathrm{R}_{2}$ from linear or one के phase decay regression are given in correlation diagrams. Regressions lines are shown in correlation plots with $95 \%$ confidence interval. P-values were calculated using Pearson correlation coefficient which is a measure of linear correlation. For the correlation matrix (Figure 6D) p-values of correlations were corrected for multiple comparisons with twostage linear step-up procedure of Benjamini, Krieger and Yekutieli with a false discovery rate (FDR) of $1 \%$. The thereby generated q-values are shown with a greyscale code.

\section{Acknowledgments}

This work was supported by the National Research, Development and Innovation OfficeNKFI through project FK 124240 and FIKP program TUDFO/47138-1/2019-ITM. Furthermore, this work was in part funded by the Austrian Science Fund (FWF) grant number P31923 (to C.R. Kowol and P. Heffeter). S. Hager is a recipient of a DOC Fellowship of the Austrian Academy of Sciences. The funding sources had no involvement in collection, analysis and interpretation of data as well as in the decision to submit the article for publication.

\section{Author Disclosure Statement:}

The authors declare no conflict of interest. 


\section{List of Abbreviations}

AA - ascorbic acid

AMA - antimycin A

$\mathrm{dd}$ - double distilled

DHE - dihydroethidium

DMSO - dimethyl sulfoxide

Dp44mT - di-2-pyridylketone 4,4-dimethyl-3-thiosemicarbazone

DpC-di-2-pyridylketone 4-cyclohexyl-4-methyl-3-thiosemicarbazone

DTT - dithiothreitol

EDTA - ethylenediaminetetraacetic acid

ER - endoplasmic reticulum

FDR - false discovery rate

FTSC - 2-formylpyridine thiosemicarbazone

GSEA - gene set enrichment analysis

GSH - glutathione

HEPES - 4-(2-hydroxyethyl)-1-piperazineethanesulfonic acid

MDR - multidrug resistant

MES - 2-(N-morpholino)ethanesulfonic acid

MT - metallothionein

MTT - 3-(4,5-dimethylthiazol-2-yl)-2,5-diphenyltetrazolium bromide

$N A C-N$-acetyl cysteine

NBT- nitroblue tetrazolium

PDI - protein disulfide isomerase

P-gp - P-glycoprotein (ABCB1)

PTSC - pyridine-2-carbaldehyde thiosemicarbazone

$\mathrm{RR}$ - ribonucleotide reductase

ROS - reactive oxygen species

SOD - superoxide dismutase

TSC - thiosemicarbazone

UV-vis - UV-visible 


\section{References}

1. Antholine W, Knight J, Whelan H, Petering DH. Studies of the reaction of 2formylpyridine thiosemicarbazone and its iron and copper complexes with biological systems. Mol Pharmacol 13: 89-98, 1977.

2. Bacher F, Domotor O, Kaltenbrunner M, Mojovic M, Popovic-Bijelic A, Graslund A, Ozarowski A, Filipovic L, Radulovic S, Enyedy EA, Arion VB. Effects of terminal dimethylation and metal coordination of proline-2-formylpyridine thiosemicarbazone hybrids on lipophilicity, antiproliferative activity, and hR2 RNR inhibition. Inorg Chem 53: 12595-609, 2014.

3. Brady DC, Crowe MS, Turski ML, Hobbs GA, Yao X, Chaikuad A, Knapp S, Xiao K, Campbell SL, Thiele DJ, Counter CM. Copper is required for oncogenic BRAF signalling and tumorigenesis. Nature 509: 492-6, 2014.

4. Covington AK, Dickinson T. Physical chemistry of organic solvent systems London, New York,: Plenum Press; 1973. x, 823 p. p.

5. Domotor O, May NV, Pelivan K, Kiss T, Keppler BK, Kowol CR, Enyedy EA. A comparative study of alpha-N-pyridyl thiosemicarbazones: Spectroscopic properties, solution stability and copper(II) complexation. Inorg Chim Acta 472: 264-275, 2018.

6. Enyedy EA, Nagy NV, Zsigo E, Kowol CR, Arion VB, Keppler BK, Kiss T. Comparative Solution Equilibrium Study of the Interactions of Copper(II), Iron(II) and Zinc(II) with Triapine (3-Aminopyridine-2-carbaldehyde Thiosemicarbazone) and Related Ligands. Eur J Inorg Chem: 1717-1728, 2010.

7. Enyedy EA, Primik MF, Kowol CR, Arion VB, Kiss T, Keppler BK. Interaction of Triapine and related thiosemicarbazones with iron(III)/(II) and gallium(III): a comparative solution equilibrium study. Dalton Trans 40: 5895-5905, 2011.

8. Felcman J, da Silva JJ. Complexes of oxovanadium(IV) with polyaminocarboxylic acids. Talanta 30: 565-70, 1983. 
9. Furedi A, Toth S, Szebenyi K, Pape VF, Turk D, Kucsma N, Cervenak L, Tovari J,

Szakacs G. Identification and Validation of Compounds Selectively Killing Resistant Cancer: Delineating Cell Line-Specific Effects from P-Glycoprotein-Induced Toxicity. Mol Cancer Ther 16: 45-56, 2017.

10. Gaetke LM, Chow-Johnson HS, Chow CK. Copper: toxicological relevance and mechanisms. Arch Toxicol 88: 1929-1938, 2014.

11. Garcia-Tojal J, Gil-Garcia R, Fouz VI, Madariaga G, Lezama L, Galletero MS, Borras J, Nollmann Fl, Garcia-Giron C, Alcaraz R, Cavia-Saiz M, Muniz P, Palacios O, Samper KG, Rojo T. Revisiting the thiosemicarbazonecopper(II) reaction with glutathione. Activity against colorectal carcinoma cell lines. J Inorg Biochem 180: 69-79, 2018.

12. Giles FJ, Fracasso PM, Kantarjian HM, Cortes JE, Brown RA, Verstovsek S, Alvarado Y, Thomas DA, Faderl S, Garcia-Manero G, Wright LP, Samson T, Cahill A, Lambert P, Plunkett W, Sznol M, DiPersio JF, Gandhi V. Phase I and pharmacodynamic study of Triapine, a novel ribonucleotide reductase inhibitor, in patients with advanced leukemia. Leuk Res 27: 1077-83, 2003.

13. Hager S, Korbula K, Bielec B, Grusch M, Pirker C, Schosserer M, Liendl L, Lang M, Grillari J, Nowikovsky K, Pape VFS, Mohr T, Szakacs G, Keppler BK, Berger W, Kowol CR, Heffeter P. The thiosemicarbazone Me2NNMe2 induces paraptosis by disrupting the ER thiol redox homeostasis based on protein disulfide isomerase inhibition. Cell Death Dis 9: 1052, 2018.

14. Hancock CN, Stockwin LH, Han B, Divelbiss RD, Jun JH, Malhotra SV, Hollingshead MG, Newton DL. A copper chelate of thiosemicarbazone NSC 689534 induces oxidative/ER stress and inhibits tumor growth in vitro and in vivo. Free Radic Biol Med 50: 110-21, 2011.

15. Hartinger CG, Zorbas-Seifried S, Jakupec MA, Kynast B, Zorbas H, Keppler BK. From bench to bedside - preclinical and early clinical development of the anticancer agent indazolium trans-[tetrachlorobis(1H-indazole)ruthenate(III)] (KP1019 or FFC14A). J Inorg Biochem 100: 891-904, 2006.

16. Heffeter P, Pape VFS, Enyedy EA, Keppler BK, Szakacs G, Kowol CR. Anticancer Thiosemicarbazones: Chemical Properties, Interaction with Iron Metabolism, and Resistance Development. Antioxid Redox Signal 30: 1062-1082, 2019. 
17. Heffeter $P$, Pongratz $M$, Steiner $E$, Chiba $P$, Jakupec MA, Elbling L, Marian B, Korner W, Sevelda F, Micksche M, Keppler BK, Berger W. Intrinsic and acquired forms of resistance against the anticancer ruthenium compound KP1019 [indazolium trans[tetrachlorobis(1H-indazole)ruthenate (III)] (FFC14A). J Pharmacol Exp Ther 312: 281-9, 2005.

18. Irving HM, Miles MG, Pettit LD. A Study of Some Problems in Determining Stoicheiometric Proton Dissociation Constants of Complexes by Potentiometric Titrations Using a Glass Electrode. Anal Chim Acta 38: 475-+, 1967.

19. Ishiguro K, Lin ZP, Penketh PG, Shyam K, Zhu R, Baumann RP, Zhu YL, Sartorelli AC, Rutherford TJ, Ratner ES. Distinct mechanisms of cell-kill by triapine and its terminally dimethylated derivative Dp44mT due to a loss or gain of activity of their copper(II) complexes. Biochem Pharmacol 91: 312-22, 2014.

20. Jansson PJ, Sharpe PC, Bernhardt PV, Richardson DR. Novel thiosemicarbazones of the ApT and DpT series and their copper complexes: identification of pronounced redox activity and characterization of their antitumor activity. J Med Chem 53: 5759-69, 2010.

21. Jansson PJ, Yamagishi T, Arvind A, Seebacher N, Gutierrez E, Stacy A, Maleki S, Sharp D, Sahni S, Richardson DR. Di-2-pyridylketone 4,4-dimethyl-3-thiosemicarbazone (Dp44mT) overcomes multidrug resistance by a novel mechanism involving the hijacking of lysosomal P-glycoprotein (Pgp). J Biol Chem 290: 9588-603, 2015.

22. Jungwirth U, Kowol CR, Keppler BK, Hartinger CG, Berger W, Heffeter P. Anticancer activity of metal complexes: involvement of redox processes. Antioxid Redox Signal 15: 1085-127, 2011.

23. Kalinowski DS, Stefani C, Toyokuni S, Ganz T, Anderson GJ, Subramaniam NV, Trinder D, Olynyk JK, Chua A, Jansson PJ, Sahni S, Lane DJ, Merlot AM, Kovacevic Z, Huang ML, Lee CS, Richardson DR. Redox cycling metals: Pedaling their roles in metabolism and their use in the development of novel therapeutics. Biochim Biophys Acta 1863: 727-48, 2016. 
24. Kallus S, Uhlik L, van Schoonhoven S, Pelivan K, Berger W, Enyedy EA, Hofmann T, Heffeter P, Kowol CR, Keppler BK. Synthesis and biological evaluation of biotinconjugated anticancer thiosemicarbazones and their iron(III) and copper(II) complexes. J Inorg Biochem 190: 85-97, 2019.

25. Karp JE, Giles FJ, Gojo I, Morris L, Greer J, Johnson B, Thein M, Sznol M, Low J. A phase I study of the novel ribonucleotide reductase inhibitor 3-aminopyridine-2carboxaldehyde thiosemicarbazone (3-AP, Triapine) in combination with the nucleoside analog fludarabine for patients with refractory acute leukemias and aggressive myeloproliferative disorders. Leuk Res 32: 71-7, 2008.

26. Kontoghiorghes GJ, Efstathiou A, Loannou-Loucaides S, Kolnagou A. Chelators controlling metal metabolism and toxicity pathways: Applications in cancer prevention, diagnosis and treatment. Hemoglobin 32: 217-227, 2008.

27. Kowol CR, Heffeter P, Miklos W, Gille L, Trondl R, Cappellacci L, Berger W, Keppler BK. Mechanisms underlying reductant-induced reactive oxygen species formation by anticancer copper(II) compounds. J Biol Inorg Chem 17: 409-23, 2012.

28. Kowol CR, Miklos W, Pfaff S, Hager S, Kallus S, Pelivan K, Kubanik M, Enyedy EA, Berger W, Heffeter P, Keppler BK. Impact of Stepwise NH2-Methylation of Triapine on the Physicochemical Properties, Anticancer Activity, and Resistance Circumvention. J Med Chem 59: 6739-52, 2016.

29. Kowol CR, Trondl R, Heffeter P, Arion VB, Jakupec MA, Roller A, Galanski M, Berger W, Keppler BK. Impact of metal coordination on cytotoxicity of 3-aminopyridine-2carboxaldehyde thiosemicarbazone (triapine) and novel insights into terminal dimethylation. J Med Chem 52: 5032-43, 2009.

30. Kunos CA, Ivy SP. Triapine Radiochemotherapy in Advanced Stage Cervical Cancer. Front Oncol 8: 149, 2018.

31. L. Zékány IN. Computational Methods for the Determination of Stability Constants. In: Computational Methods for the Determination of Stability Constants. edited by Leggett DJ. New York: Springer US; 1985. pp. 291-353. 
32. Laszlo V, Hoda MA, Garay T, Pirker C, Ghanim B, Klikovits T, Dong YW, Rozsas A, Kenessey I, Szirtes I, Grusch M, Jakopovic M, Samarzija M, Brcic L, Kern I, Rozman A, Popper H, Zochbauer-Muller S, Heller G, Altenberger C, Ziegler B, Klepetko W, Berger W, Dome B, Hegedus B. Epigenetic down-regulation of integrin alpha7 increases migratory potential and confers poor prognosis in malignant pleural mesothelioma. J Pathol 237: 203-14, 2015.

33. Lee D, Kim IY, Saha S, Choi KS. Paraptosis in the anti-cancer arsenal of natural products. Pharmacol Ther 162: 120-33, 2016.

34. Lovejoy DB, Jansson PJ, Brunk UT, Wong J, Ponka P, Richardson DR. Antitumor activity of metal-chelating compound Dp44mT is mediated by formation of a redoxactive copper complex that accumulates in lysosomes. Cancer Res 71: 5871-80, 2011.

35. Lovejoy DB, Sharp DM, Seebacher N, Obeidy P, Prichard T, Stefani C, Basha MT, Sharpe PC, Jansson PJ, Kalinowski DS, Bernhardt PV, Richardson DR. Novel secondgeneration di-2-pyridylketone thiosemicarbazones show synergism with standard chemotherapeutics and demonstrate potent activity against lung cancer xenografts after oral and intravenous administration in vivo. J Med Chem 55: 7230-44, 2012.

36. Malarz K, Mrozek-Wilczkiewicz A, Serda M, Rejmund M, Polanski J, Musiol R. The role of oxidative stress in activity of anticancer thiosemicarbazones. Oncotarget 9: 17689-17710, 2018.

37. Maleki Vareki S, Salim KY, Danter WR, Koropatnick J. Novel anti-cancer drug COTI-2 synergizes with therapeutic agents and does not induce resistance or exhibit crossresistance in human cancer cell lines. PLoS One 13: e0191766, 2018.

38. McGivern TJP, Afsharpour S, Marmion CJ. Copper complexes as artificial DNA metallonucleases: From Sigman's reagent to next generation anti-cancer agent? Inorg Chim Acta 472: 12-39, 2018.

39. Merlot AM, Porter GM, Sahni S, Lim EG, Peres P, Richardson DR. The metastasis suppressor, NDRG1, differentially modulates the endoplasmic reticulum stress response. Biochim Biophys Acta Mol Basis Dis 1865: 2094-2110, 2019. 
40. Pape VF, Toth S, Furedi A, Szebenyi K, Lovrics A, Szabo P, Wiese M, Szakacs G. Design, synthesis and biological evaluation of thiosemicarbazones, hydrazinobenzothiazoles and arylhydrazones as anticancer agents with a potential to overcome multidrug resistance. Eur J Med Chem 117: 335-54, 2016.

41. Pham AN, Xing GW, Miller CJ, Waite TD. Fenton-like copper redox chemistry revisited: Hydrogen peroxide and superoxide mediation of copper-catalyzed oxidant production. Journal of Catalysis 301: 54-64, 2013.

42. Ritchie ME, Phipson B, Wu D, Hu Y, Law CW, Shi W, Smyth GK. limma powers differential expression analyses for RNA-sequencing and microarray studies. Nucleic Acids Res 43: e47, 2015.

43. Ruttkay-Nedecky B, NejdI L, Gumulec J, Zitka O, Masarik M, Eckschlager T, Stiborova M, Adam V, Kizek R. The role of metallothionein in oxidative stress. Int J Mol Sci 14: 6044-66, 2013.

44. Santoro A, Vileno B, Palacios O, Peris-Diaz MD, Riegel G, Gaiddon C, Krezel A, Faller P. Reactivity of $\mathrm{Cu}(\mathrm{ii})-, \mathrm{Zn}(\mathrm{ii})-$ and $\mathrm{Fe}(\mathrm{ii})$-thiosemicarbazone complexes with glutathione and metallothionein: from stability to dissociation to transmetallation. Metallomics 11: 994-1004, 2019.

45. Schafer FQ, Buettner GR. Redox environment of the cell as viewed through the redox state of the glutathione disulfide/glutathione couple. Free Radical Bio Med 30: 1191-1212, 2001.

46. Seebacher NA, Richardson DR, Jansson PJ. A mechanism for overcoming Pglycoprotein-mediated drug resistance: novel combination therapy that releases stored doxorubicin from lysosomes via lysosomal permeabilization using Dp44mT or DpC. Cell Death Dis 7: e2510, 2016.

47. Serda M, Kalinowski DS, Rasko N, Potuckova E, Mrozek-Wilczkiewicz A, Musiol R, Malecki JG, Sajewicz M, Ratuszna A, Muchowicz A, Golab J, Simunek T, Richardson DR, Polanski J. Exploring the anti-cancer activity of novel thiosemicarbazones generated through the combination of retro-fragments: dissection of critical structure-activity relationships. PLoS One 9: e110291, 2014. 
48. Shao J, Zhou B, Di Bilio AJ, Zhu L, Wang T, Qi C, Shih J, Yen Y. A Ferrous-Triapine complex mediates formation of reactive oxygen species that inactivate human ribonucleotide reductase. Mol Cancer Ther 5: 586-92, 2006.

49. Shimada K, Reznik E, Stokes ME, Krishnamoorthy L, Bos PH, Song Y, Quartararo CE, Pagano NC, Carpizo DR, deCarvalho AC, Lo DC, Stockwell BR. Copper-Binding Small Molecule Induces Oxidative Stress and Cell-Cycle Arrest in Glioblastoma-PatientDerived Cells. Cell Chem Biol 25: 585-594 e7, 2018.

50. Sperandio S, de Belle I, Bredesen DE. An alternative, nonapoptotic form of programmed cell death. Proc Natl Acad Sci U S A 97: 14376-81, 2000.

51. Srivastava S, Blower PJ, Aubdool AA, Hider RC, Mann GE, Siow RC. Cardioprotective effects of $\mathrm{Cu}((\mathrm{II}))$ ATSM in human vascular smooth muscle cells and cardiomyocytes mediated by Nrf2 and DJ-1. Sci Rep 6: 7, 2016.

52. Stacy AE, Palanimuthu D, Bernhardt PV, Kalinowski DS, Jansson PJ, Richardson DR. Structure-Activity Relationships of Di-2-pyridylketone, 2-Benzoylpyridine, and 2Acetylpyridine Thiosemicarbazones for Overcoming Pgp-Mediated Drug Resistance. J Med Chem 59: 8601-20, 2016.

53. Trondl R, Flocke LS, Kowol CR, Heffeter P, Jungwirth U, Mair GE, Steinborn R, Enyedy EA, Jakupec MA, Berger W, Keppler BK. Triapine and a more potent dimethyl derivative induce endoplasmic reticulum stress in cancer cells. Mol Pharmacol 85: 451-9, 2014.

54. Turk D, Hall MD, Chu BF, Ludwig JA, Fales HM, Gottesman MM, Szakacs G. Identification of compounds selectively killing multidrug-resistant cancer cells. Cancer Res 69: 8293-301, 2009.

55. Windt T, Toth S, Patik I, Sessler J, Kucsma N, Szepesi A, Zdrazil B, Ozvegy-Laczka C, Szakacs G. Identification of anticancer OATP2B1 substrates by an in vitro triplefluorescence-based cytotoxicity screen. Arch Toxicol 93: 953-964, 2019.

56. Yee KW, Cortes J, Ferrajoli A, Garcia-Manero G, Verstovsek S, Wierda W, Thomas D, Faderl S, King I, O'Brien S M, Jeha S, Andreeff M, Cahill A, Sznol M, Giles FJ. Triapine and cytarabine is an active combination in patients with acute leukemia or myelodysplastic syndrome. Leuk Res 30: 813-22, 2006. 
57. Yu Y, Gutierrez E, Kovacevic Z, Saletta F, Obeidy P, Suryo Rahmanto Y, Richardson DR. Iron chelators for the treatment of cancer. Curr Med Chem 19: 2689-702, 2012.

58. $\mathrm{Yu} Y$, Suryo Rahmanto $\mathrm{Y}$, Hawkins $\mathrm{CL}$, Richardson DR. The potent and novel thiosemicarbazone chelators di-2-pyridylketone-4,4-dimethyl-3-thiosemicarbazone and 2-benzoylpyridine-4,4-dimethyl-3-thiosemicarbazone affect crucial thiol systems required for ribonucleotide reductase activity. Mol Pharmacol 79: 921-31, 2011.

59. Zeidner JF, Karp JE, Blackford AL, Smith BD, Gojo I, Gore SD, Levis MJ, Carraway HE, Greer JM, Ivy SP, Pratz KW, McDevitt MA. A phase II trial of sequential ribonucleotide reductase inhibition in aggressive myeloproliferative neoplasms. Haematologica 99: 672-8, 2014.

60. Zhang C. Essential functions of iron-requiring proteins in DNA replication, repair and cell cycle control. Protein Cell 5: 750-60, 2014. 
Table 1: Structure and $\mathrm{IC}_{50}(72 \mathrm{~h})$ values of tested compounds in SW480 cells.

Compound Structure $\quad \mathrm{TSC}^{\mathrm{IC}} \mathrm{C}_{50}(\mu \mathrm{M}) \quad \mathrm{Cu}-\mathrm{TSC}_{\mathrm{IC}}(\mu \mathrm{M})$

FTSC

PTSC

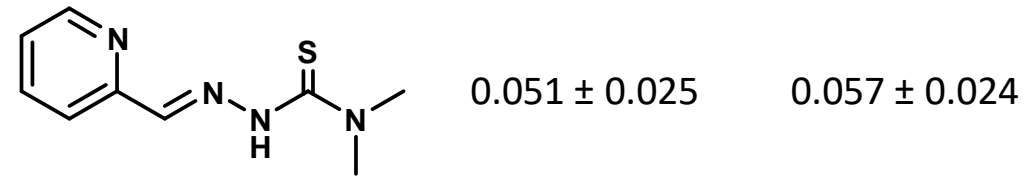

Triapine

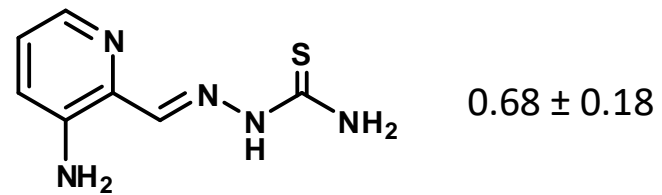

$1.19 \pm 0.61$

$\mathrm{H}_{2} \mathrm{NNHMe}$



$3.13 \pm 1.48$

$\mathrm{H}_{2} \mathrm{NNMe}_{2}$

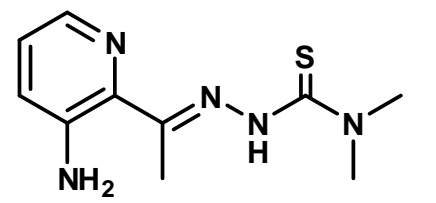

$0.80 \pm 0.12$

$1.62 \pm 0.28$

$\mathrm{MeHNNMe}_{2}$<smiles>CNc1cccnc1/C(C)=N/NC(=S)N(C)C</smiles>

$2.28 \pm 0.17$

$3.30 \pm 0.83$

$\mathrm{Me}_{2} \mathrm{NNH}_{2}$<smiles>C/C(=N\NC(N)=S)c1ncccc1N(C)C</smiles>

$8.51 \pm 1.18$

$4.97 \pm 1.57$

$\mathrm{Me}_{2} \mathrm{NNHMe}$<smiles>CNC(=S)N/N=C(\C)c1ncccc1N(C)C</smiles>

$0.93 \pm 0.38$ 
$\mathrm{Me}_{2} \mathrm{NNMe}_{2}$<smiles>C/C(=N\NC(=S)N(C)C)c1ncccc1N(C)C</smiles>

$0.038 \pm 0.012 \quad 0.066 \pm 0.020$

Dp44mT<smiles>CN(C)C(=S)NN=C(c1ccccn1)c1ccccn1</smiles>

$0.047 \pm 0.018 \quad 0.034 \pm 0.013$

DpC<smiles>CN(C(=S)NN=C(c1ccccn1)c1ccccn1)C1CCCCC1</smiles> 
Table 2: IC $\mathrm{C}_{50}(72 \mathrm{~h})$ values of tested compounds in MES-SA and MES-SA/Dx5 cells.

\begin{tabular}{|c|c|c|c|c|}
\hline & $\mathrm{TSC} \mathrm{IC}_{50}(\mu \mathrm{M})$ & & Cu-TSC IC $50(\mu)$ & \\
\hline & MES-SA & $\begin{array}{l}\text { MES-SA/Dx5 } \\
\text { (resistance factor) }\end{array}$ & MES-SA & $\begin{array}{l}\text { MES-SA/Dx5 } \\
\text { (resistance factor) }\end{array}$ \\
\hline FTSC & $1.87 \pm 0.22$ & $8.11 \pm 0.94$ (4.3) & $9.45 \pm 0.49$ & $4.31 \pm 0.72(0.46)$ \\
\hline PTSC & $0.129 \pm 0.032$ & $0.029 \pm 0.003(0.22)$ & $0.081 \pm 0.046$ & $0.024 \pm 0.005(0.30)$ \\
\hline Triapine & $0.63 \pm 0.09$ & $2.58 \pm 0.33(4.1)$ & $2.44 \pm 0.47$ & $16.86 \pm 2.15(6.9)$ \\
\hline $\mathrm{H}_{2} \mathrm{NNHMe}$ & $0.86 \pm 0.10$ & $4.05 \pm 0.39(4.7)$ & $6.75 \pm 1.31$ & $21.35 \pm 3.35(3.2)$ \\
\hline $\mathrm{H}_{2} \mathrm{NNMe}_{2}$ & $0.51 \pm 0.13$ & $0.76 \pm 0.17(1.5)$ & $2.57 \pm 0.47$ & $4.19 \pm 0.24(1.6)$ \\
\hline $\mathrm{MeHNNMe}_{2}$ & $0.99 \pm 0.12$ & $2.76 \pm 0.00(2.8)$ & $6.22 \pm 1.43$ & $2.13 \pm 0.47(0.34)$ \\
\hline $\mathrm{Me}_{2} \mathrm{NNH}_{2}$ & $3.51 \pm 0.55$ & $3.29 \pm 0.74(0.94)$ & $9.91 \pm 1.22$ & $3.24 \pm 0.29(0.33)$ \\
\hline $\mathrm{Me}_{2} \mathrm{NNHMe}$ & $2.57 \pm 0.31$ & $2.24 \pm 0.51(0.87)$ & $3.58 \pm 0.97$ & $1.13 \pm 0.13(0.32)$ \\
\hline $\mathrm{Me}_{2} \mathrm{NNMe}_{2}$ & $0.013 \pm 0.002$ & $0.004 \pm 0.001(0.31)$ & $0.030 \pm 0.018$ & $0.008 \pm 0.002(0.27)$ \\
\hline Dp44mT & $0.029 \pm 0.015$ & $0.006 \pm 0.001(0.21)$ & $0.066 \pm 0.039$ & $0.004 \pm 0.001(0.06)$ \\
\hline $\mathrm{DpC}$ & $0.034 \pm 0.027$ & $0.003 \pm 0.002(0.09)$ & $0.009 \pm 0.007$ & $0.001 \pm 0.0008(0.11)$ \\
\hline
\end{tabular}


Table 3: $\mathrm{p} K_{\mathrm{a}}$ values of the TSC ligands determined by spectrophotometric titrations and overall stability constants for the copper(II) TSC complexes $(\log 6){ }^{*}$ calculated from the conditional stability constants $\left(\log 6^{\prime}{ }_{5.9}\right.$ of $\left.[\mathrm{CuL}]^{+}\right)$and $\mathrm{p} K_{\mathrm{a}}$ values of the copper(II) complexes. $\mathrm{pCu}=-\log [\mathrm{Cu}(\mathrm{II})]$ values calculated at $\mathrm{pH} 7.4 \mathrm{C}_{\mathrm{Cu}(\mathrm{II})}=\mathrm{C}_{\mathrm{TSC}}=1 \mu \mathrm{M}$ and fraction of $[\mathrm{CuL}(\mathrm{OH})]$.

\begin{tabular}{|c|c|c|c|c|c|c|c|c|}
\hline \multirow[t]{2}{*}{ ligand } & $\begin{array}{l}\text { mediu } \\
\mathrm{m}\end{array}$ & $\begin{array}{l}\mathrm{p} K_{\mathrm{a}} \\
\left(\mathrm{H}_{2} \mathrm{~L}^{+}\right.\end{array}$ & $\mathrm{p} K_{\mathrm{a}}(\mathrm{HL})$ & $\begin{array}{l}\log 6 \\
{[\mathrm{CuLH}]^{2}}\end{array}$ & $\begin{array}{l}\log \theta \\
{[\mathrm{CuL}]}\end{array}$ & $\begin{array}{l}\log B \\
{[\mathrm{CuL}(\mathrm{OH})}\end{array}$ & $\mathrm{pCu}$ & $\begin{array}{l}\% \\
{[\mathrm{CuL}(\mathrm{OH})}\end{array}$ \\
\hline & & ) & & + & + & ] & & ] \\
\hline \multirow[t]{3}{*}{ FTSC } & $\mathrm{H}_{2} \mathrm{O}$ & 3.48 & $10.72 \pm 0.0$ & 20.34 & 18.26 & 9.56 & 11.9 & 4.8 \\
\hline & & \pm & 1 & & & & 6 & \\
\hline & & 0.01 & & & & & & \\
\hline
\end{tabular}

$\begin{array}{llllllll}\text { PTSC } \quad \mathrm{H}_{2} \mathrm{O} & 3.61 & 10.22 \pm 0.0 & 21.05 & 18.96 & 10.40 & 13.1 & 6.5 \\ & \pm & 1 & & & & 7 & \\ & 0.01 & & & & & \end{array}$

$\begin{array}{lllllllll}\text { Triapine }^{*} & \mathrm{H}_{2} \mathrm{O} & 4.25 & 10.58 & 20.08 & 17.57 & 8.93 & 11.3 & 5.4 \\ & & & & & & & 5 & \\ \mathrm{H}_{2} \mathrm{NNHMe} & \mathrm{H}_{2} \mathrm{O} & 4.40 & 11.03 \pm 0.0 & 20.26 & 17.72 & 9.10 & 11.1 & 5.7 \\ & & \pm & 1 & & & & 2 & \\ & & & & & & & & \end{array}$

$\begin{array}{lllllllll}\mathrm{H}_{2} \mathrm{NNMe}_{2} & \mathrm{H}_{2} \mathrm{O} & 4.64 & 10.09 \pm 0.0 & 20.84 & 18.33 & 9.68 & 12.6 & 5.3\end{array}$

$\pm \quad 1$

6

0.01

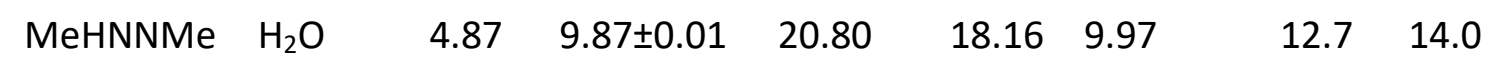

$\pm \quad 5$

0.01

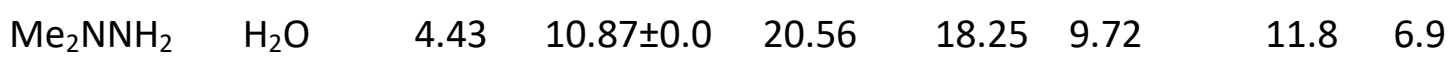


0.01

\begin{tabular}{|c|c|c|c|c|c|c|c|c|}
\hline $\mathrm{Me}_{2} \mathrm{NNHM}$ & $\mathrm{H}_{2} \mathrm{O}$ & 4.53 & $10.98 \pm 0.0$ & 21.02 & 18.45 & 10.34 & 11.9 & 16.3 \\
\hline \multirow[t]{2}{*}{ e } & & \pm & 7 & & & & 5 & \\
\hline & & 0.02 & & & & & & \\
\hline \multirow[t]{3}{*}{$\mathrm{Me}_{2} \mathrm{NNMe}_{2}$} & $\mathrm{H}_{2} \mathrm{O}$ & 4.93 & $10.69 \pm 0.0$ & 22.06 & 19.55 & 10.77 & 13.2 & 4.0 \\
\hline & & \pm & 1 & & & & 8 & \\
\hline & & 0.01 & & & & & & \\
\hline \multirow[t]{3}{*}{$\mathrm{Dp} 44 \mathrm{mT}$} & $\mathrm{H}_{2} \mathrm{O}$ & 3.44 & $10.44 \pm 0.0$ & 21.77 & 19.43 & 10.64 & 13.4 & 3.9 \\
\hline & & \pm & 1 & & & & 1 & \\
\hline & & 0.01 & & & & & & \\
\hline \multirow[t]{3}{*}{$\mathrm{DpC}$} & $5 \%$ & 3.47 & $10.71 \pm 0.0$ & - & - & - & - & - \\
\hline & DMSO & \pm & 1 & & & & & \\
\hline & & 0.01 & & & & & & \\
\hline \multirow[t]{3}{*}{$\mathrm{DpC}$} & $30 \%$ & 3.03 & $11.38 \pm 0.0$ & 19.28 & 17.15 & 7.69 & 10.1 & 0.9 \\
\hline & DMSO & \pm & 6 & & & & 7 & \\
\hline & & 0.06 & & & & & & \\
\hline \multirow[t]{2}{*}{$\mathrm{DpC}^{\dagger}$} & $\mathrm{H}_{2} \mathrm{O}$ & 3.50 & 10.67 & 22.81 & 20.36 & 12.00 & 14.1 & 9.9 \\
\hline & & & & & & & & \\
\hline \multirow[t]{2}{*}{ Triapine ${ }^{\ddagger}$} & $30 \%$ & 3.92 & 10.78 & 16.69 & 14.35 & 4.68 & 8.55 & 0.5 \\
\hline & DMSO & & & & & & & \\
\hline \multirow[t]{2}{*}{$\mathrm{H}_{2} \mathrm{NNMe}_{2}{ }^{\ddagger}$} & $30 \%$ & 4.31 & 10.29 & 17.05 & 15.12 & 5.63 & 9.38 & 0.8 \\
\hline & DMSO & & & & & & & \\
\hline
\end{tabular}


40

Table 4: Calculated observed rate constants $\left(k_{\text {obs }}\right)$ and half-lives $\left(t_{1 / 2}\right)$ in the copper(II) - TSC

- GSH (1:1:50) systems from the spectral changes at the $\lambda_{\max }$ of the copper(II) complex and absorbance values measured at $1 \mathrm{~h}$ compared to that of the ligand.

\begin{tabular}{|c|c|c|c|c|}
\hline & $k_{\text {obs }}\left(\min ^{-1}\right)$ & $t_{1 / 2}(\min )$ & $\lambda(\mathrm{nm})$ & $\begin{array}{l}\text { fraction of non- } \\
\text { reduced } \mathrm{Cu}(\mathrm{II})- \\
\text { complex at } 1 \mathrm{~h}(\%)\end{array}$ \\
\hline FTSC & $4.13 \times 10^{-2}$ & 17 & 380 & 10 \\
\hline PTSC $^{*}$ & $4.30 \times 10^{-4}$ & 1615 & 394 & 90 \\
\hline Triapine $^{+}$ & $1.10 \times 10^{-1}$ & 6 & 420 & 4 \\
\hline $\mathrm{H}_{2} \mathrm{NNHMe}$ & $7.70 \times 10^{-2}$ & 9 & 420 & 10 \\
\hline $\mathrm{H}_{2} \mathrm{NNMe}_{2}$ & $1.60 \times 10^{-2}$ & 44 & 424 & 61 \\
\hline $\mathrm{MeHNNMe}_{2}$ & $1.12 \times 10^{-2}$ & 62 & 450 & 57 \\
\hline $\mathrm{Me}_{2} \mathrm{NNH}_{2}$ & $4.47 \times 10^{-2}$ & 16 & 416 & 24 \\
\hline $\mathrm{Me}_{2} \mathrm{NNHMe}$ & $3.90 \times 10^{-2}$ & 18 & 420 & 20 \\
\hline $\mathrm{Me}_{2} \mathrm{NNMe}_{2}$ & $6.97 \times 10^{-4}$ & 1019 & 422 & 92 \\
\hline Dp44mT & $2.12 \times 10^{-3}$ & 329 & 412 & 80 \\
\hline $\mathrm{DpC}$ & $2.30 \times 10^{-3}$ & 298 & 422 & 85 \\
\hline FTSC & $4.13 \times 10^{-2}$ & 17 & 380 & 10 \\
\hline PTSC $^{\dagger}$ & $4.30 \times 10^{-4}$ & 1615 & 394 & 90 \\
\hline \multicolumn{5}{|c|}{$k_{\mathrm{obs}}=1.03 \times 10^{-3} \mathrm{~min}^{-1}, t_{1 / 2}=675 \mathrm{~min}$ in the presence of 100 eq. GSH (20). ${ }^{\dagger} k_{\mathrm{obs}}=6.30 \times 10^{-}$} \\
\hline
\end{tabular}


Figure Legends
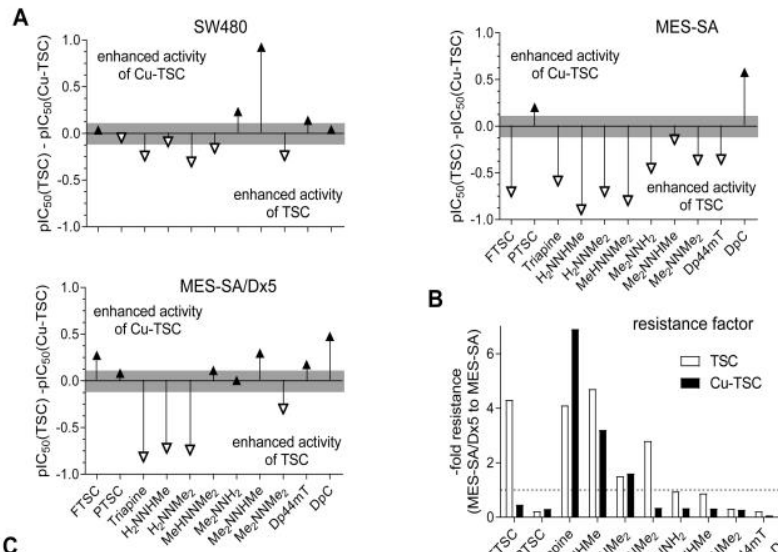

B
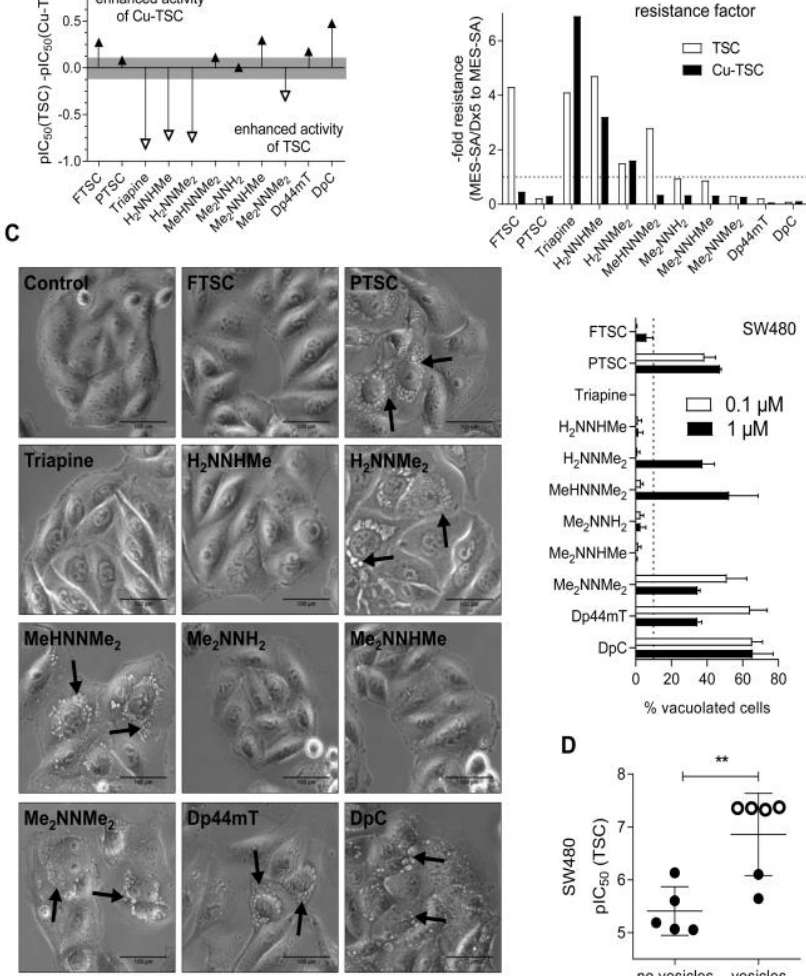

SW480, $1 \mu \mathrm{M}, 24 \mathrm{~h}$
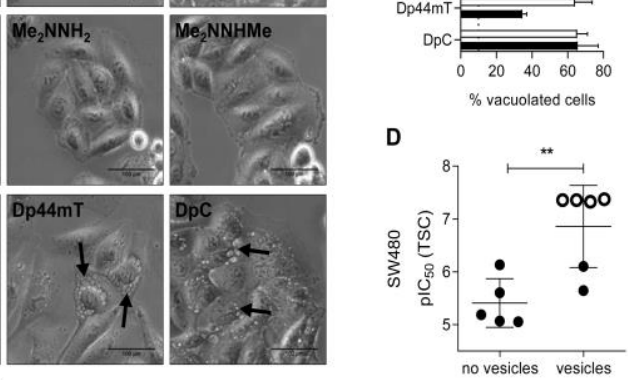

Figure 1: Change of anticancer activity upon complexation with copper(II) and potential of the tested TSC panel to induce paraptosis. A: Differences of logarithmic anticancer activity of the metal-free ligand to the respective copper in the indicated cell lines complex $\left[\mathrm{plC} 50\right.$ (TSC) - $\left.\mathrm{plC}_{50}(\mathrm{Cu}-\mathrm{TSC})\right] . \mathrm{IC}_{50}$ values were determined in mono- or co-culture as described in the Materials and Methods section after $72 \mathrm{~h}$. B: Fold resistance of MESSA/Dx5 compared to MES-SA cells against either the metal-free TSCs or the respective copper(II) complexes (CU-TSC). C: Representative microscopy images of SW480 cells treated with $1 \mu \mathrm{M}$ of the indicated metal-free TSCs for $24 \mathrm{~h}$. Arrows indicate the cytoplasmic vesicles. Scale bar: $100 \mu \mathrm{m}$. The graph on the right shows the percentage of cytoplasmic vesicles observed after treatment of SW480 cells with 0.1 or $1 \mu \mathrm{M}$ metal-free TSC for $24 \mathrm{~h}$. Values given are mean \pm standard deviation of three areas per well of two 
independent experiments. Line indicates $10 \%$ threshold of vesicle induction. D: Metal-free compounds inducing vesicles (threshold: $10 \%$ ) at $1 \mu \mathrm{M}$ in SW480 cells also showed a higher anticancer activity in the nanomolar range $\left[\mathrm{plC}_{50}=-\log \left(\mathrm{IC} \mathrm{C}_{50}\right)\right]$. Significance between groups Was calculated using T-test by two-tailed t-test using GraphPad Prism software ${ }^{* *} \mathrm{p}<$ 0.01). Open symbols indicate nanomolar-active TSCs. 

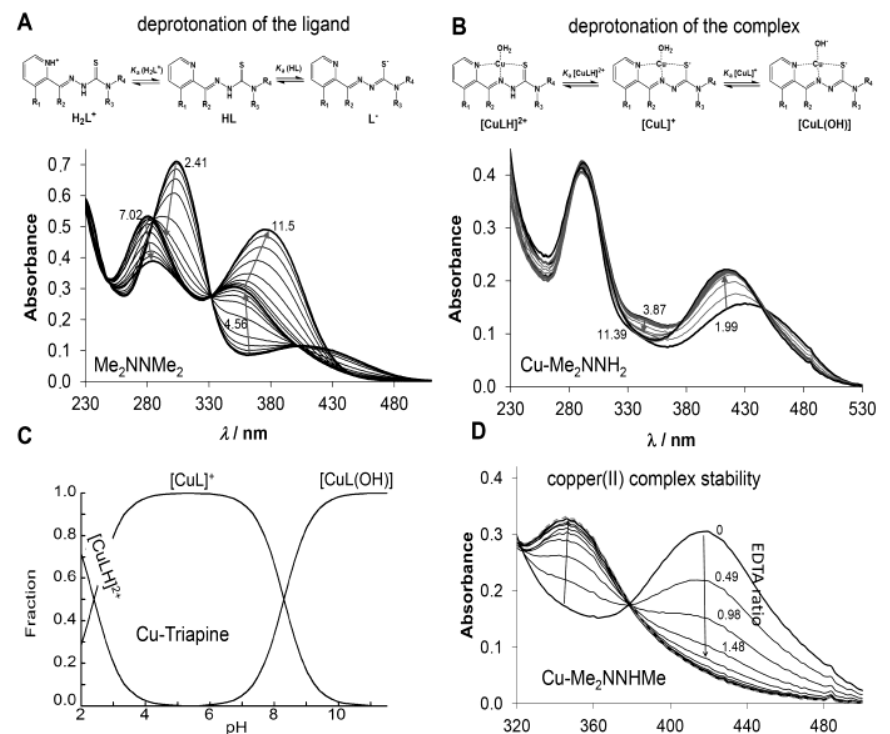

E

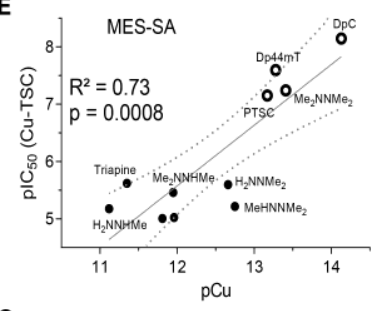

G
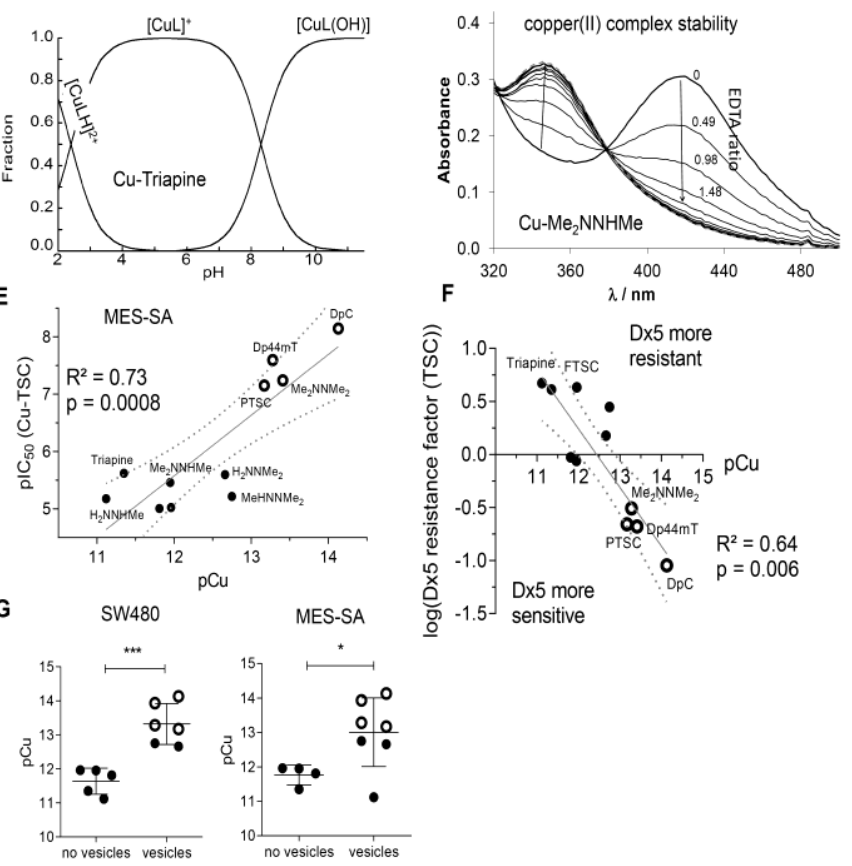

Figure 2: Higher copper(II) complex stability correlates with increased anticancer activity.

A: UV-vis spectra of $\mathrm{Me}_{2} \mathrm{NNMe}_{2}(40 \mu \mathrm{M})$ recorded at $\mathrm{pH}$ values between 2 and 11.9 and scheme for stepwise deprotonation of metal-free TSCs. B: UV-vis spectra of the copper(II) complex of $\mathrm{Me}_{2} \mathrm{NNH}_{2}(25 \mu \mathrm{M})$ recorded at $\mathrm{pH}$ values between 2 and 11.5 and scheme of stepwise deprotonation of TSC copper(II) complexes. C: Speciation curves of CU-Triapine system depending on pH. D: UV-vis spectra of the copper(II) complex of $\mathrm{Me}_{2} \mathrm{NNMeH}$ (25 $\mu \mathrm{M}$ ) in the presence of EDTA at various ratios (EDTA to complex, $\mathrm{C}_{\text {EDTA }}=0-175 \mu \mathrm{M}$ ) and the spectrum of the metal-free $\mathrm{Me}_{2} \mathrm{NNMeH}$ (grey dashed line) at pH 5.9. E: Correlation of $\mathrm{pCu}$ $[-\log (\mathrm{Cu}(\mathrm{II}))]$ values, representing copper(II) complex stability, to anticancer activity $\left(\mathrm{pIC}_{50}\right.$ values) of the TSC copper complexes in MES-SA cells. $R^{2}$ and $p$ values have been calculated using Graph Pad Prism software. F: Correlation of $\mathrm{pCu}$ to the logarithmic resistance factor 
to the metal-free TSCs of MES-SA/Dx5 cells compared to parental MES-SA cells. $R^{2}$ and $p$ values have been calculated using Graph Pad prism software. G: Grouping of the compounds by vesicle induction (threshold: $10 \%$ ) at $1 \mu \mathrm{M}$ treatment metal-free ligand of SW480 for $24 \mathrm{~h}$ or MES-SA cells for $48 \mathrm{~h}$ showed a higher complex stability in vesicle$\stackrel{2}{0}$ inducing TSCs. Significance between groups was calculated by two-tailed T-test using GraphPad Prism software $(* * * p<0.001, * p<0.05)$. Open symbols indicate nanomolaractive TSCs. 

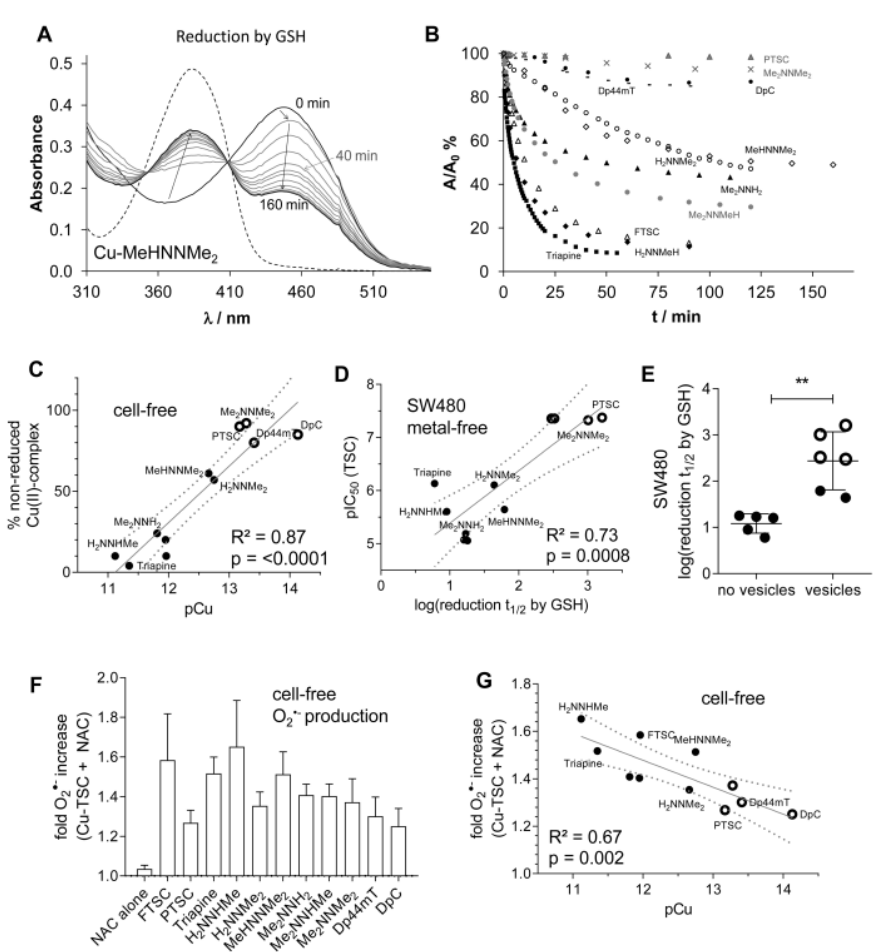

Figure 3: Cell-free reduction rate and superoxide production of copper(II) complexes and their correlation with biological activity. A: Time dependence of the UV-vis spectra of the MeHNNMe $_{2}$ copper(II) complex $(25 \mu \mathrm{M})$ in the presence of 50 equivalents $\mathrm{GSH}(1.25 \mathrm{mM})$ and the spectrum of the metal-free ligand (dashed line) at $\mathrm{pH} 7.4$ under $\mathrm{O}_{2}$-free condition. B: Decrease of absorbance (in $\% A / A_{0}$ ) recorded at $\lambda_{\max }$ of the different copper(II) TSC complexes over time at the same conditions given in $\mathbf{A}$. Symbols: Triapine ( $\boldsymbol{\square}), \mathrm{H}_{2} \mathrm{NNHMe}$ $(\bullet), \operatorname{FTSC}(\boldsymbol{\Delta}), \mathrm{Me}_{2} \mathrm{NNHMe}(\bullet), \mathrm{Me}_{2} \mathrm{NNH}_{2}(\boldsymbol{\Delta}), \operatorname{MeHNNMe}_{2}(\bullet), \mathrm{H}_{2} \mathrm{NNMe}_{2}(\bullet), \operatorname{Dp} 44 m T(-)$, $\operatorname{DpC}(\bullet), \mathrm{Me}_{2} \mathrm{NNMe}_{2}(\boldsymbol{x})$ and PTSC $(\boldsymbol{\Delta})$. C: Correlation of pCu to the $\%$ of non-reduced copper(II) complexes calculated from GSH reduction studies. D: Correlations of the logarithmic reduction half-life of the TSC complexes by GSH to the anticancer activity $\left(\mathrm{pIC}_{50}\right.$ values) of metal-free ligands or copper(II) complexes in SW480 cells. $R^{2}$ and $p$ values have been calculated using Graph Pad prism software. E: Grouping of the compounds by vesicle induction (threshold: $10 \%$ ) at $1 \mu \mathrm{M}$ treatment metal-free ligand for $48 \mathrm{~h}$ in SW480 cells showed a slower copper(II) complex reduction by GSH in vesicle-inducing TSCs. Significance between groups was calculated by two-tailed T-test using GraphPad Prism software $(* * p<0.01)$. Open symbols indicate nanomolar-active TSCs. F: Fold increase of superoxide levels by $5 \mu \mathrm{M}$ treatment of indicated TSC copper(II) complexes in the presence 
of 2 mM NAC was evaluated by the cell-free NBT assay. Values given are mean \pm standard deviation of duplicates of two independent experiments. G: Correlation of $\mathrm{pCu}$ (indicating

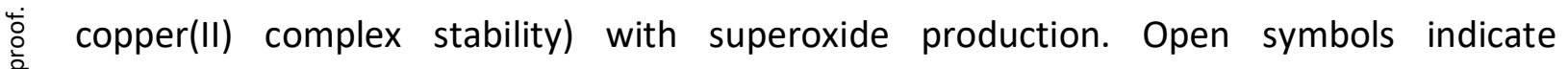
nanomolar-active TSCs. $R^{2}$ and $p$ values have been calculated using Graph Pad prism software. 
A

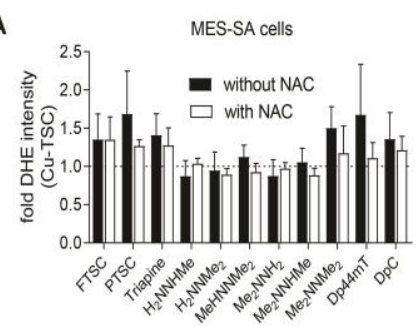

C

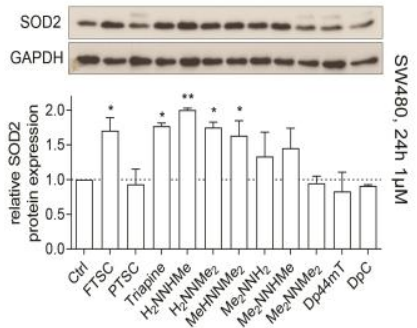

D

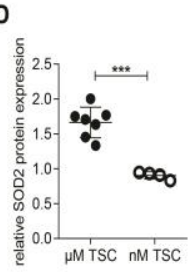

F



G
B

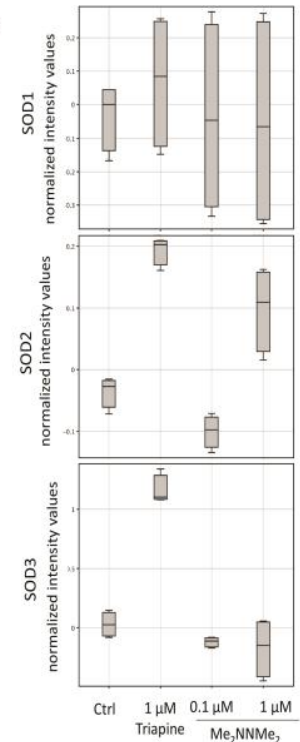

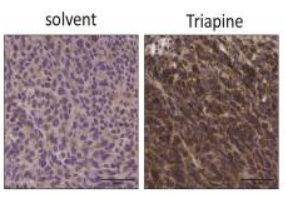
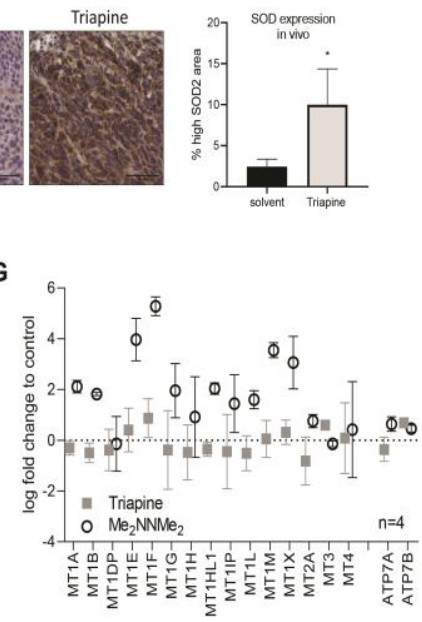

Figure 4: Upregulated redox stress signaling after TSC treatment. A: Intracellular superoxide production measured by flow cytometry of DHE fluorescence of MES-SA cells treated with $5 \mu \mathrm{M}$ of indicated TSC with or without $2 \mathrm{mM}$ NAC for $1 \mathrm{~h}$. Values given are mean \pm standard deviation of at least three independent experiments. B: Normalized mRNA expression values for SOD1/2/3 of SW480 cells untreated or treated with $0.1 \mu \mathrm{M}$ $\mathrm{Me}_{2} \mathrm{NNMe}_{2}, 1 \mu \mathrm{M} \mathrm{Me}_{2} \mathrm{NNMe}_{2}$ or $1 \mu \mathrm{M}$ Triapine for $15 \mathrm{~h}$ were assessed by whole genome gene expression analysis performed with two technical replicates from two biological replicates. Normalization and annotation was performed with GeneSpring software (Agilent). C: Western blot analysis of SOD2 expressed by SW480 cells treated with $1 \mu \mathrm{M}$ of the indicated TSC for $24 \mathrm{~h}$. GAPDH was used as a loading control. Densitometric 
quantification using ImageJ of two separate experiments is given as mean \pm standard deviation. Significance to control was calculated by one-way Anova and Dunnett's multiple comparison test using GraphPad Prism software (** $p<0.01, * p<0.05)$. D: Micromolaractive TSC-treated SW480 cells express higher protein levels of SOD2 than nanomolaractive TSC-treated cells. Open symbols indicate nanomolar active TSCs. E: Female Balb/c mice bearing subcutaneous CT-26 tumors were treated with solvent $(10 \%$ DMSO, $n=4)$ or Triapine $(10 \mathrm{mg} / \mathrm{kg}, \mathrm{n}=4)$ p.o. for 5 consecutive days a week for two weeks. Tumor were sampled and paraffin-embedded for immunohistochemical stain of SOD2. Representative images of the stain are depicted (scalebar $=50 \mu \mathrm{m}$ ). Percent highly positive SOD2-stained area of whole tissue slides were analysed by Definiens software. Significanct difference to solvent group was calculated by one-way ANOVA with Dunnett's multiple comparison test (* $p<0.05)$. F: GSEA from whole-genome gene expression data revealed significant enrichment in genes of the Gene Ontology term "Response to zinc ion" in SW480 cells treated with $1 \mu \mathrm{M} \mathrm{Me}{ }_{2} \mathrm{NNMe}_{2}$ compared to untreated cells. Normalized enrichment score (NES) and false discovery rate (FDR) are given. G: Upregulation of metallothioneins and copper transporter ATP7A/B mainly contributed to the enrichment of the Gene Ontology term "Response to zinc ion" as seen by their individual mRNA expression levels given as mean log fold change to control \pm standard deviation. 

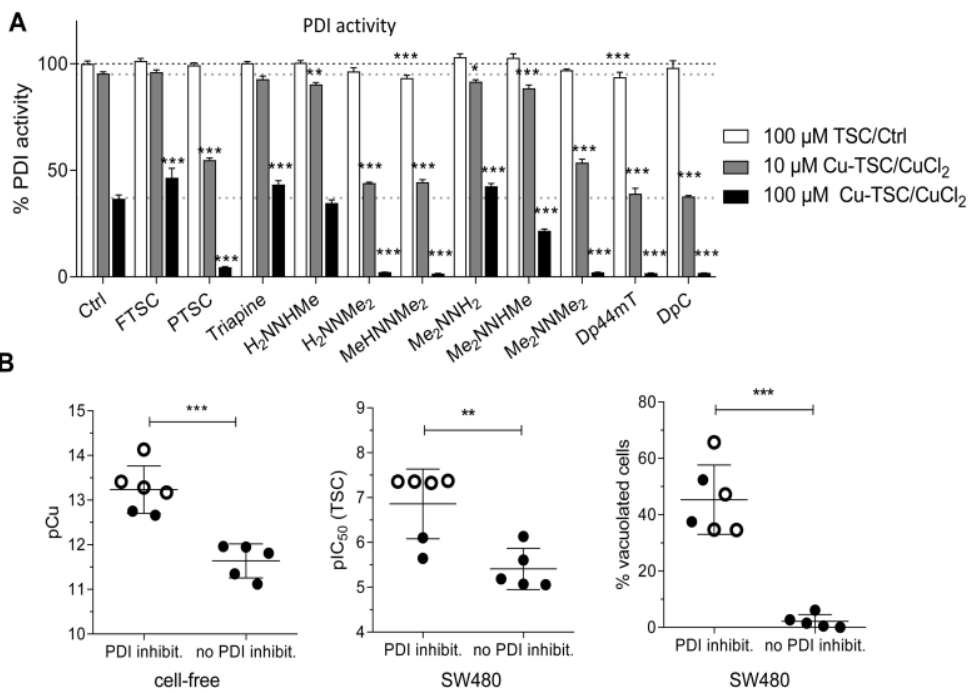

C

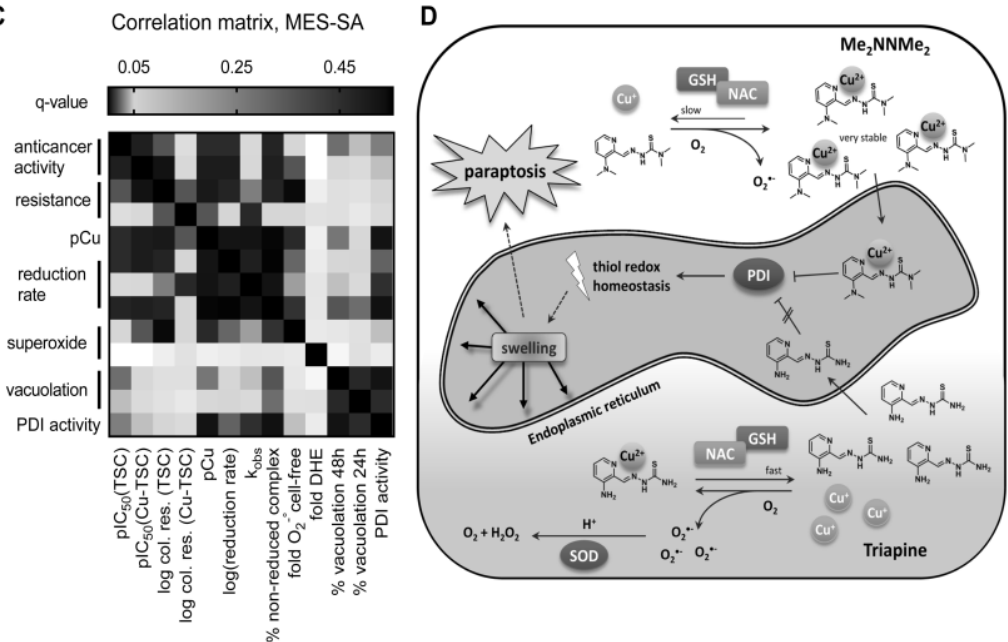

Figure 5: Inhibition of PDI by TSC copper(II) complexes. A: PDI activity was measured with 10 or $100 \mu \mathrm{M}$ of indicated TSC copper(II) complexes or copper alone using the PROTEOSTAT PDI assay kit. B: TSC complexes that inhibit PDI above levels of copper ions alone also showed higher $\mathrm{pCu}$ (indicating copper(II) complex stability), anticancer activity (in SW480 cells) and vesicle formation (in SW480 cells). Open symbols indicate nanomolaractive TSCs. C: Correlation matrix of measured chemical and biological parameters in MESSA cells. P-values corrected for multiple comparisons (q-value) with an FDR of $1 \%$ are indicated with grayscale and were calculated with GraphPad Prism 8. Labels on x-axis are grouped thematically on the $y$-axis for a better overview. D: Differences in the proposed mode of action of nanomolar-active TSCs (represented by $\mathrm{Me}_{2} \mathrm{NNMe}_{2}$ ) and micromolaractive TSCs (represented by Triapine). 
Suppl. Table 1: $I C_{50}(3$ and $24 \mathrm{~h}$ ) values of tested compounds in SW480 cells

\begin{tabular}{lllll}
\hline & \multicolumn{2}{l}{ TSC IC 50 Cu-TSC IC ${ }_{50}(\mu \mathrm{M})$} \\
\hline & $3 \mathrm{~h}$ & $24 \mathrm{~h}$ & $3 \mathrm{~h}$ & $24 \mathrm{~h}$ \\
\hline FTSC & $>25$ & $>25$ & $>25$ & $10.39 \pm 2.70$ \\
PTSC & $>25$ & $>25$ & $4.43 \pm 1.66$ & $0.42 \pm 0.21$ \\
Triapine & $>25$ & $>25$ & $>25$ & $>25$ \\
$\mathrm{H}_{2} \mathrm{NNHMe}$ & $>25$ & $>25$ & $>25$ & $>25$ \\
$\mathrm{H}_{2} \mathrm{NNMe}_{2}$ & $>25$ & $>25$ & $>25$ & $19.85 \pm 3.87$ \\
$\mathrm{MeHNNMe}_{2}$ & $>25$ & $>25$ & $32.18 \pm 3.01$ & $7.32 \pm 0.78$ \\
$\mathrm{Me}_{2} \mathrm{NNH}_{2}$ & $>25$ & $>25$ & $34.15 \pm 3.03$ & $7.90 \pm 1.06$ \\
$\mathrm{Me}_{2} \mathrm{NNHMe}$ & $>25$ & $>25$ & $15.20 \pm 2.76$ & $2.14 \pm 0.33$ \\
$\mathrm{Me}_{2} \mathrm{NNMe}_{2}$ & $>25$ & $>25$ & $6.51 \pm 0.57$ & $0.60 \pm 0.11$ \\
$\mathrm{Dp} 44 m T$ & $>25$ & $>25$ & $6.24 \pm 0.33$ & $0.40 \pm 0.16$ \\
DpC & $>25$ & $16.97 \pm 2.15$ & $5.03 \pm 1.88$ & $0.78 \pm 0.19$ \\
\hline
\end{tabular}


Suppl. Table 1: $\mathrm{IC}_{50}$ ( 3 and $24 \mathrm{~h}$ ) values of tested compounds in SW480 cells

51

\begin{tabular}{lllll}
\hline & \multicolumn{2}{l}{ TSC IC 50 Cu-TSC IC 50 ( $\mu \mathrm{MM})$} \\
\hline & $3 \mathrm{~h}$ & $24 \mathrm{~h}$ & $3 \mathrm{~h}$ & $24 \mathrm{~h}$ \\
\hline FTSC & $>25$ & $>25$ & $>25$ & $10.39 \pm 2.70$ \\
PTSC & $>25$ & $>25$ & $4.43 \pm 1.66$ & $0.42 \pm 0.21$ \\
Triapine & $>25$ & $>25$ & $>25$ & $>25$ \\
$\mathrm{H}_{2} \mathrm{NNHMe}$ & $>25$ & $>25$ & $>25$ & $>25$ \\
$\mathrm{H}_{2} \mathrm{NNMe}_{2}$ & $>25$ & $>25$ & $>25$ & $19.85 \pm 3.87$ \\
$\mathrm{MeHNNMe}_{2}$ & $>25$ & $>25$ & $32.18 \pm 3.01$ & $7.32 \pm 0.78$ \\
$\mathrm{Me}_{2} \mathrm{NNH}_{2}$ & $>25$ & $>25$ & $34.15 \pm 3.03$ & $7.90 \pm 1.06$ \\
$\mathrm{Me}_{2} \mathrm{NNHMe}$ & $>25$ & $>25$ & $15.20 \pm 2.76$ & $2.14 \pm 0.33$ \\
$\mathrm{Me}_{2} \mathrm{NNMe}_{2}$ & $>25$ & $>25$ & $6.51 \pm 0.57$ & $0.60 \pm 0.11$ \\
$\mathrm{Dp} 44 \mathrm{mT}$ & $>25$ & $>25$ & $6.24 \pm 0.33$ & $0.40 \pm 0.16$ \\
DpC & $>25$ & $16.97 \pm 2.15$ & $5.03 \pm 1.88$ & $0.78 \pm 0.19$ \\
\hline
\end{tabular}


Suppl. Table 3: $I C_{50}(24 \mathrm{~h})$ values of tested compounds in MES-SA and MESSA/Dx5 cells.

\begin{tabular}{lllll}
\hline & \multicolumn{2}{l}{ TSC IC 50 Cu-TSC IC 50 ( $(\mu \mathrm{M})$} \\
\hline & MES-SA & MES-SA/Dx5 & MES-SA & MES-SA/Dx5 \\
\hline FTSC & $>25$ & $>25$ & $>25$ & $>25$ \\
PTSC & $1.98 \pm 0.23$ & $>25$ & $1.45 \pm 0.37$ & $>25$ \\
Triapine & $>25$ & $>25$ & $>25$ & $>25$ \\
$\mathrm{H}_{2} \mathrm{NNHMe}$ & $>25$ & $>25$ & $>25$ & $>25$ \\
$\mathrm{H}_{2} \mathrm{NNMe}_{2}$ & $>25$ & $>25$ & $>25$ & $>25$ \\
$\mathrm{MeHNNMe}_{2}$ & $>25$ & $21.55 \pm 5.14$ & $19.78 \pm 2.61$ & $14.74 \pm 1.45$ \\
$\mathrm{Me}_{2} \mathrm{NNH}_{2}$ & $>25$ & $24.99 \pm 0.33$ & $>25$ & $26.47 \pm 0.74$ \\
$\mathrm{Me}_{2} \mathrm{NNHMe}$ & $>25$ & $>25$ & $>25$ & $>25$ \\
$\mathrm{Me}_{2} \mathrm{NNMe}_{2}$ & $>25$ & $>25$ & $>25$ & $13.54 \pm 0.91$ \\
Dp44mT & $3.04 \pm 0.24$ & $13.33 \pm 0.94$ & $1.29 \pm 0.46$ & $7.43 \pm 0.57$ \\
DpC & $11.43 \pm 0.61$ & $>25$ & $5.93 \pm 0.59$ & 16.37 \\
\hline
\end{tabular}


Suppl. Table 4: $\mathrm{IC}_{50}(144 \mathrm{~h})$ values of tested compounds in MES-SA and MES-SA/Dx5 cells

\begin{tabular}{|c|c|c|c|c|}
\hline & MES-SA & MES-SA/Dx5 & MES-SA & MES-SA/Dx5 \\
\hline FTSC & $1.43 \pm 0.18$ & $9.00 \pm 0.96$ & $10.66 \pm 0.55$ & $3.93 \pm 0.85$ \\
\hline PTSC & $0.0365 \pm 0.0089$ & $0.0163 \pm 0.0026$ & $0.0268 \pm 0.0096$ & $0.0129 \pm 0.0025$ \\
\hline Triapine & $0.53 \pm 0.07$ & $2.84 \pm 0.38$ & $1.94 \pm 0.32$ & $20.49 \pm 2.55$ \\
\hline $\mathrm{H}_{2} \mathrm{NNHMe}$ & $0.71 \pm 0.10$ & $4.91 \pm 0.28$ & $4.13 \pm 0.41$ & $32.06 \pm 2.66$ \\
\hline $\mathrm{H}_{2} \mathrm{NNMe}_{2}$ & $0.41 \pm 0.09$ & $0.87 \pm 0.21$ & $2.40 \pm 0.27$ & $4.44 \pm 0.06$ \\
\hline $\mathrm{MeHNNMe}_{2}$ & $1.04 \pm 0.05$ & $1.15 \pm 0.13$ & $5.06 \pm 0.79$ & $1.59 \pm 0.30$ \\
\hline $\mathrm{Me}_{2} \mathrm{NNH}_{2}$ & $4.02 \pm 0.43$ & $3.97 \pm 0.57$ & $10.41 \pm 0.47$ & $3.09 \pm 0.14$ \\
\hline $\mathrm{Me}_{2} \mathrm{NNHMe}$ & $2.76 \pm 0.34$ & $2.19 \pm 0.35$ & $2.83 \pm 0.54$ & $1.02 \pm 0.04$ \\
\hline $\mathrm{Me}_{2} \mathrm{NNMe}_{2}$ & $0.0084 \pm 0.0024$ & $0.0028 \pm 0.0003$ & $0.0131 \pm 0.0037$ & $0.0034 \pm 0.0008$ \\
\hline $\mathrm{Dp} 44 \mathrm{mT}$ & $0.0127 \pm 0.0034$ & $0.0040 \pm 0.0007$ & $0.0058 \pm 0.0013$ & $0.0021 \pm 0.0005$ \\
\hline $\mathrm{DpC}$ & $0.0052 \pm 0.0014$ & $0.0023 \pm 0.0006$ & $0.0032 \pm 0.0008$ & $0.0013 \pm 0.0003$ \\
\hline
\end{tabular}


Suppl. Table 5: Calculated $\lambda_{\max }(\mathrm{nm})$ and $\varepsilon\left(\mathrm{M}^{-1} \mathrm{~cm}^{-1}\right)$ values of the ligand species in the different protonation states.

\begin{tabular}{|c|c|c|c|c|}
\hline \multirow[b]{2}{*}{ ligand } & \multirow[b]{2}{*}{ medium } & \multicolumn{3}{|c|}{$\lambda_{\max }(\mathrm{nm}) / \varepsilon\left(\mathrm{M}^{-1} \mathrm{~cm}^{-1}\right)$} \\
\hline & & $\mathrm{H}_{2} \mathrm{~L}^{+}$ & HL & $\mathrm{L}^{-}$ \\
\hline Triapine & $\mathrm{H}_{2} \mathrm{O}$ & 394 / 18860 & $358 / 15000$ & $368 / 17450$ \\
\hline $\mathrm{H}_{2} \mathrm{NNHMe}$ & $\mathrm{H}_{2} \mathrm{O}$ & $390 / 16386$ & 354 / 12899 & $382 / 14841$ \\
\hline $\mathrm{H}_{2} \mathrm{NNMe}_{2}$ & $\mathrm{H}_{2} \mathrm{O}$ & $390 / 17300$ & $360 / 12460$ & $378 / 18875$ \\
\hline $\mathrm{MeHNNMe}_{2}$ & $\mathrm{H}_{2} \mathrm{O}$ & $408 / 15290$ & $382 / 11230$ & $394 / 17810$ \\
\hline $\mathrm{Me}_{2} \mathrm{NNH}_{2}$ & $\mathrm{H}_{2} \mathrm{O}$ & 412 / 8140 & $348 / 9450$ & $366 / 12830$ \\
\hline $\mathrm{Me}_{2} \mathrm{NNHMe}$ & $\mathrm{H}_{2} \mathrm{O}$ & $413 / 10240$ & $349 / 12200$ & $378 / 16930$ \\
\hline $\mathrm{Me}_{2} \mathrm{NNMe}_{2}$ & $\mathrm{H}_{2} \mathrm{O}$ & $411 / 2900$ & 350 / 7793 & 377 / 12990 \\
\hline FTSC & $\mathrm{H}_{2} \mathrm{O}$ & 342 / 22003 & $310 / 22924$ & $342 / 17187$ \\
\hline PTSC & $\mathrm{H}_{2} \mathrm{O}$ & 334 / 17323 & $306 / 16104$ & $354 / 14966$ \\
\hline Dp44mT & $\mathrm{H}_{2} \mathrm{O}$ & $344 / 16635$ & $324 / 16000$ & $376 / 13370$ \\
\hline $\mathrm{DpC}$ & $5 \%$ DMSO & $346 / 17970$ & $328 / 15040$ & $382 / 10750$ \\
\hline DpC & $30 \%$ DMSO & $348 / 18620$ & $328 / 17300$ & $388 / 15140$ \\
\hline Triapine * & $30 \%$ DMSO & $402 / 20600$ & $368 / 15600$ & $376 / 17200$ \\
\hline $\mathrm{H}_{2} \mathrm{NNMe}_{2}{ }^{*}$ & $30 \%$ DMSO & 398 / 18200 & $366 / 13600$ & $384 / 20700$ \\
\hline
\end{tabular}

* Data taken from Ref. (6) 
Suppl. Table 6: $p K_{a}$ values of the TSC copper(II) complexes determined by spectrophotometric titrations and conditional $\left(\log \beta^{\prime}\right)$ stability constants for [CuL] ${ }^{+}$ species at $\mathrm{pH} 5.90$ determined via EDTA displacement reaction

\begin{tabular}{|c|c|c|c|c|}
\hline ligand & medium & $\mathrm{p} K_{\mathrm{a}}[\mathrm{CuLH}]^{2+}$ & $\mathrm{p} K_{\mathrm{a}}[\mathrm{CuL}]^{+}$ & $\log \beta_{5.9}^{\prime}[\mathrm{CuL}]^{+}$ \\
\hline Triapine * & $\mathrm{H}_{2} \mathrm{O}$ & 2.51 & 8.64 & 12.88 \\
\hline $\mathrm{H}_{2} \mathrm{NNHMe}$ & $\mathrm{H}_{2} \mathrm{O}$ & $2.54 \pm 0.01$ & $8.62 \pm 0.01$ & $12.58 \pm 0.02$ \\
\hline $\mathrm{H}_{2} \mathrm{NNMe}_{2}$ & $\mathrm{H}_{2} \mathrm{O}$ & $2.51 \pm 0.02$ & $8.65 \pm 0.07$ & $14.12 \pm 0.01$ \\
\hline $\mathrm{MeHNNMe}_{2}$ & $\mathrm{H}_{2} \mathrm{O}$ & $2.64 \pm 0.02$ & $8.19 \pm 0.02$ & $14.15 \pm 0.03$ \\
\hline $\mathrm{Me}_{2} \mathrm{NNH}_{2}$ & $\mathrm{H}_{2} \mathrm{O}$ & $2.31 \pm 0.02$ & $8.53 \pm 0.01$ & $13.27 \pm 0.03$ \\
\hline $\mathrm{Me}_{2} \mathrm{NNHMe}$ & $\mathrm{H}_{2} \mathrm{O}$ & $2.57 \pm 0.02$ & $8.11 \pm 0.02$ & $13.35 \pm 0.02$ \\
\hline $\mathrm{Me}_{2} \mathrm{NNMe}_{2}$ & $\mathrm{H}_{2} \mathrm{O}$ & $2.51 \pm 0.01$ & $8.78 \pm 0.01$ & $14.72 \pm 0.07$ \\
\hline FTSC & $\mathrm{H}_{2} \mathrm{O}$ & $2.08 \pm 0.02$ & $8.70 \pm 0.04$ & $13.44 \pm 0.07$ \\
\hline PTSC & $\mathrm{H}_{2} \mathrm{O}$ & $2.09 \pm 0.01$ & $8.56 \pm 0.01$ & $14.64 \pm 0.01$ \\
\hline Dp44mT & $\mathrm{H}_{2} \mathrm{O}$ & $2.34 \pm 0.02$ & $8.79 \pm 0.03$ & $14.89 \pm 0.01$ \\
\hline $\mathrm{DpC}$ & $5 \%$ DMSO & - & - & - \\
\hline $\mathrm{DpC}$ & $30 \%$ DMSO & $2.13 \pm 0.03$ & $9.46 \pm 0.02$ & $11.67 \pm 0.02 \dagger$ \\
\hline $\mathrm{DpC} \neq$ & $\mathrm{H}_{2} \mathrm{O}$ & 2.45 & 8.36 & - \\
\hline Triapine $\S$ & $30 \%$ DMSO & 2.34 & 9.67 & - \\
\hline $\mathrm{H}_{2} \mathrm{NNMe}_{2} \S$ & $30 \%$ DMSO & 1.93 & 9.49 & - \\
\hline
\end{tabular}

${ }^{\star}$ Data taken from Ref. (22). ${ }^{\dagger} \log \beta_{5.90}=10.19 \pm 0.04$ for the $\mathrm{Cu}(\mathrm{II})$-EDTA complex in the $30 \%(\mathrm{w} / \mathrm{w}) \mathrm{DMSO} / \mathrm{H}_{2} \mathrm{O}$ mixture was determined via Triapine displacement reaction. ${ }^{\ddagger}$ Estimated values from $\mathrm{p} K_{\mathrm{a}}$ values of the complexes measured in the $30 \%(\mathrm{w} / \mathrm{w}) \mathrm{DMSO} / \mathrm{H}_{2} \mathrm{O}$ mixture using the slopes of the $\mathrm{pK} \mathrm{a}_{\mathrm{a}} v \mathrm{~s} .1 / \varepsilon_{\mathrm{r}}$ curves of $\mathrm{Cu}(\mathrm{II})$ complexes of Triapine and $\mathrm{H}_{2} \mathrm{NNMe}_{2}$. $\S$ Data taken from Ref. (6) 
Page 56 of 67
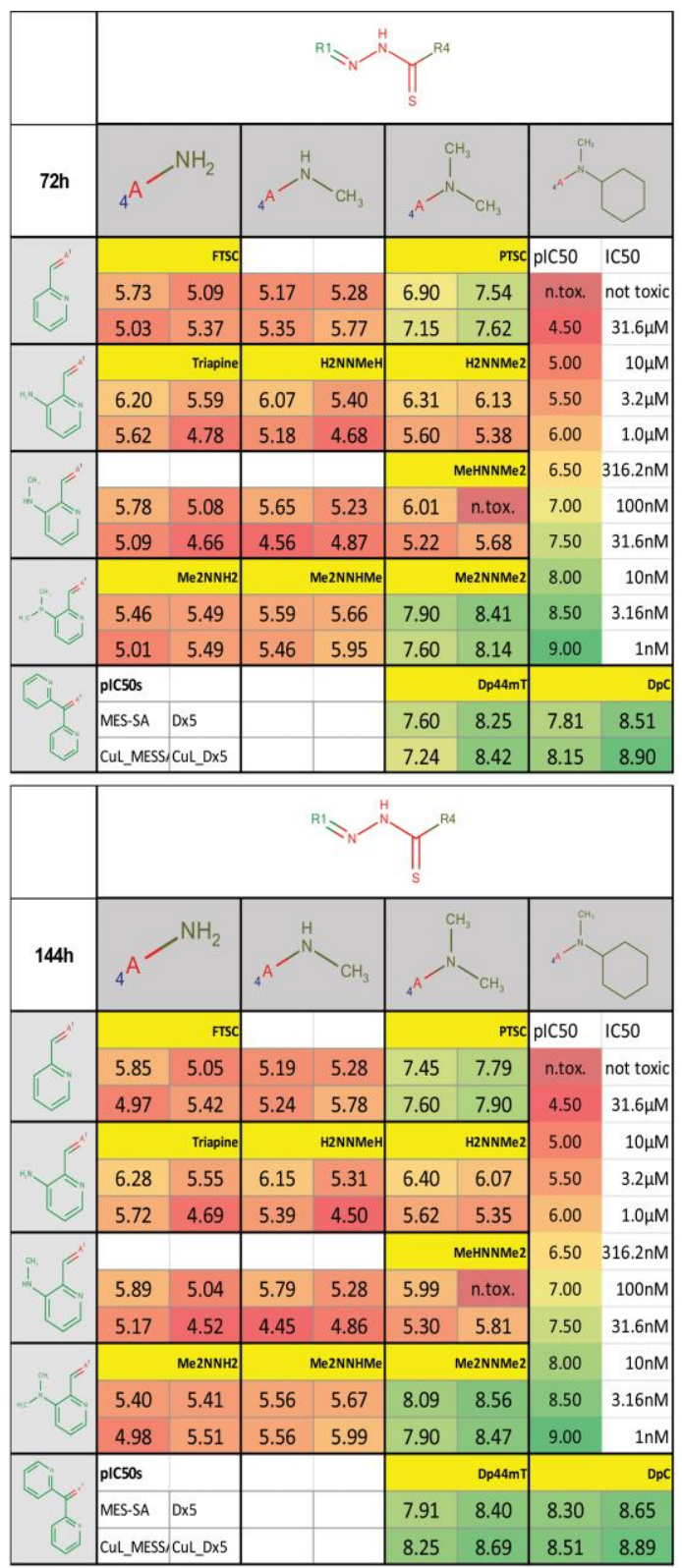

Suppl. Figure 1: Structure activity relationship matrix (SARM) showing the negative logarithmic $\mathrm{IC}_{50}$ values $\left(\mathrm{plC}_{50}\right)$ of MES-SA and MES-SA/Dx5 cells treated with our TSC panel as metal-free ligand or copper(II) complex for 72 and $144 \mathrm{~h}$. 
MES-SA

A

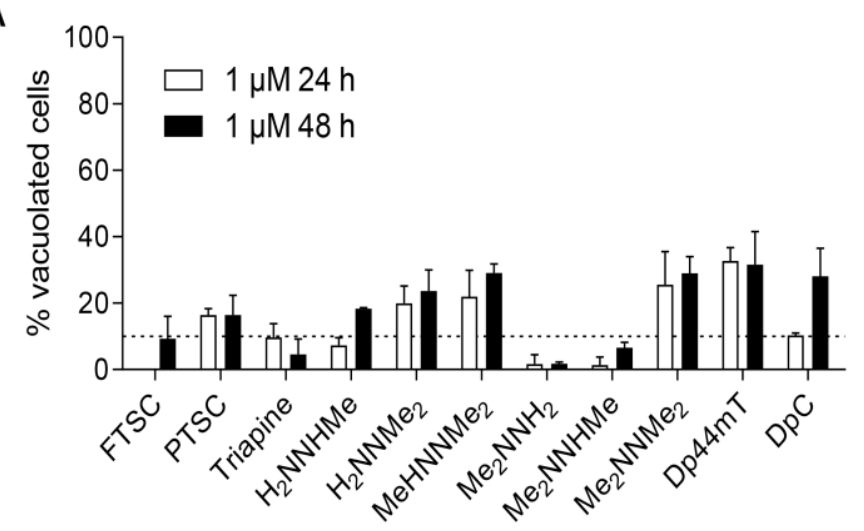

B

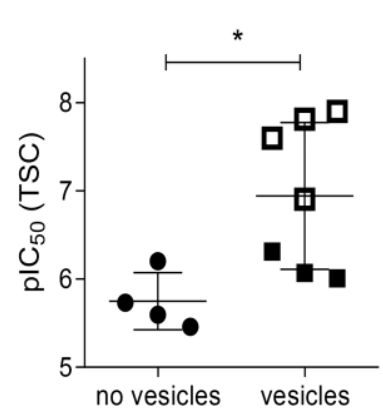

Suppl. Figure 2: A: Percentage of cytoplasmic vesicles observed after treatment of MESSA cells with $1 \mu \mathrm{M}$ metal-free TSC in medium containing $1 \%$ serum for $24 \mathrm{~h}$ or $48 \mathrm{~h}$. Values given are mean \pm standard deviation of three areas per well. Line indicates $10 \%$ threshold of vesicle induction. B: Metal-free compounds inducing vesicles (threshold: $10 \%$ ) at $1 \mu \mathrm{M}$ in MES-SA cells also showed a higher anticancer activity $\left(\mathrm{plC}_{50}=-\log _{10}\left(\mathrm{IC}_{50}\right)\right)$ in the nanomolar range. Significance between groups was calculated by two-tailed t-test using GraphPad Prism software $(* p<0.05)$ 
A

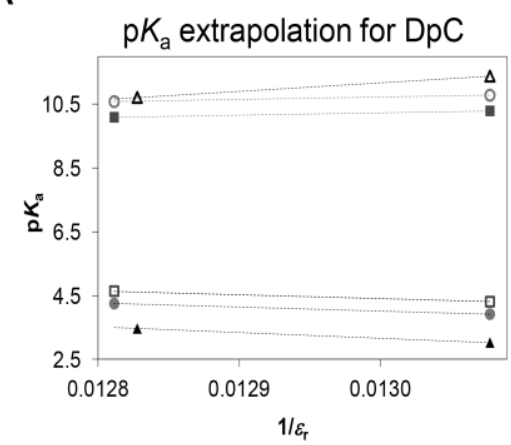

C

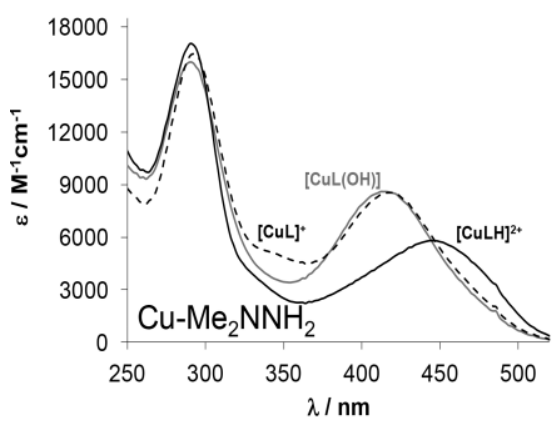

B
D

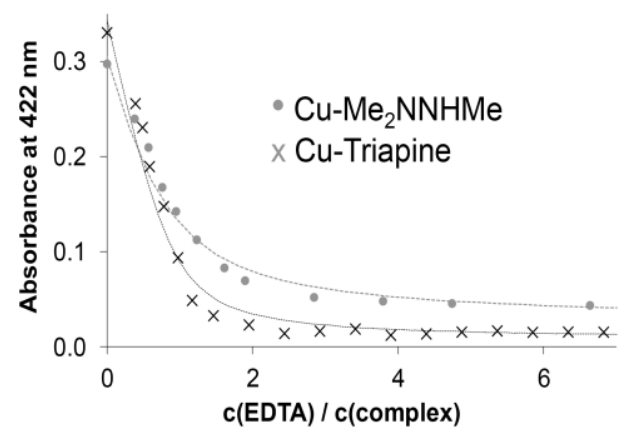

Suppl. Figure 3: A: Correlation diagram for the $p K_{a}$ values measured at various DMSO content plotted against the $1 / \varepsilon_{r}$ values of the solvent medium for Triapine $(\bullet$; $\circ), \mathrm{H}_{2} \mathrm{NNMe}_{2}(\mathbf{-} ; \square)$ and DpC $(\boldsymbol{\Delta} ; \Delta)$. B: Calculated individual absorption spectra from a measured UV-vis spectra of $\mathrm{Me}_{2} \mathrm{NNMe}_{2}(40 \mu \mathrm{M})$ recorded at $\mathrm{pH}$ values between 2 and 11.9. C: Calculated individual absorption spectra from a measured UV-vis spectra of the copper(II) complex of $\mathrm{Me}_{2} \mathrm{NNH}_{2}$ recorded at $\mathrm{pH}$ values between 2 and 11.9. D: Absorbance values recorded for copper(II)-Me $\mathrm{MNNHMe}_{2}$ EDTA $(\bullet)$ and copper(II)-Triapine-EDTA ( $\times$ ) systems at $422 \mathrm{~nm}$ with the simulated curves (dashed lines) at the various complex-to-EDTA ratios. 
A
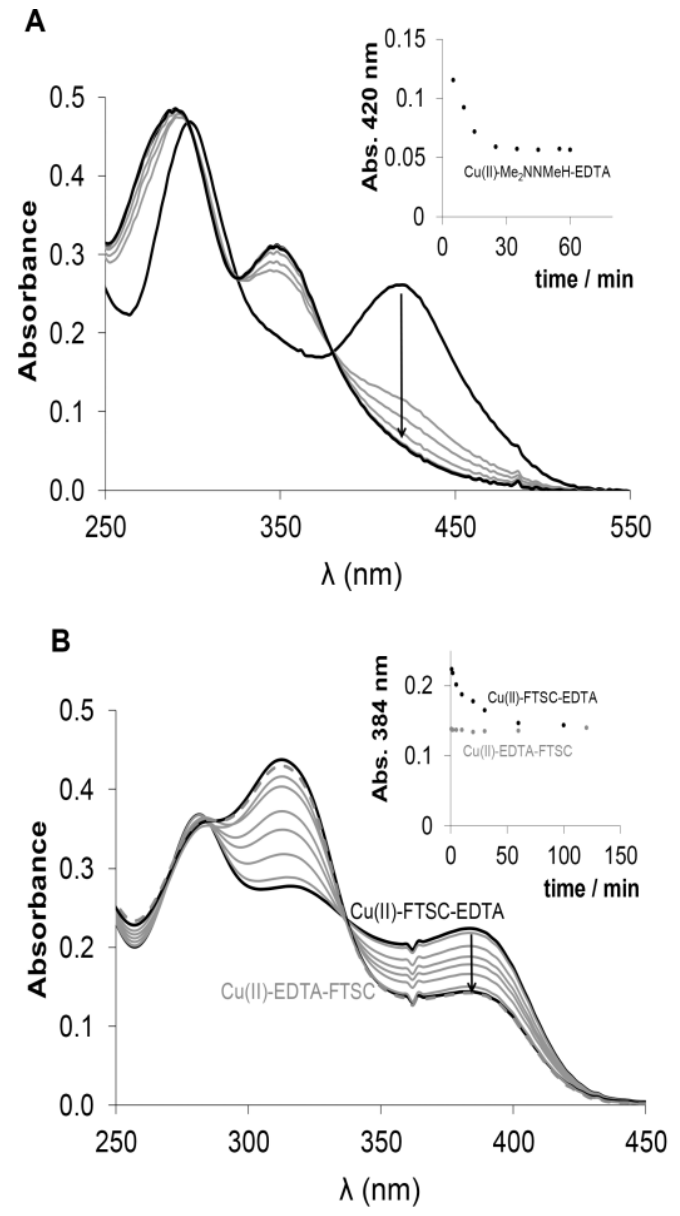

Suppl. Figure 4: Time-dependence of UV-vis spectra of the copper(II) complex of $\mathrm{Me}_{2} \mathrm{NNMeH}(\mathrm{A})$ and FTSC (B) in the presence of EDTA at 1:1 complex-to-EDTA ratio. Inserted figures show the absorbance changes at $420 \mathrm{~nm}(A)$ and at $384 \mathrm{~nm}$ (B) in dependence of time. The green dashed line in fig. B shows the absorbance spectrum recorded for the reverse reaction when 1 eq FTSC ligand was added to the copper(II)-EDTA complex after 60 min waiting time and the green symbols $(\bullet)$ show the changes of the absorbance values at $384 \mathrm{~nm}$ in time. $\left(\mathrm{c}_{\text {copper(II) }}=25 \mu \mathrm{M}\right.$, $\mathrm{C}_{\text {ligand }}=25 \mu \mathrm{M}, \mathrm{C}_{\mathrm{EDTA}}=25 \mu \mathrm{M}, \mathrm{pH} 5.9$ ). 
Page 60 of 67

A

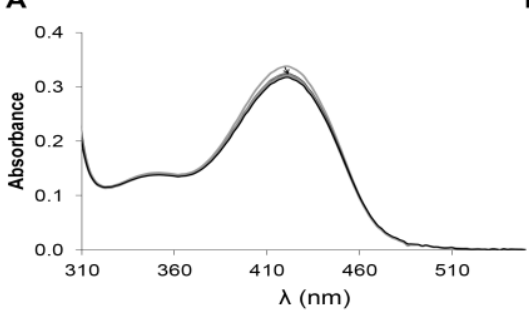

B

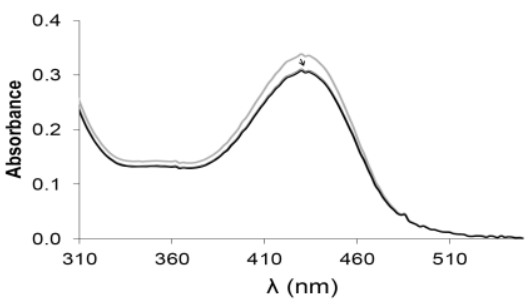

Suppl. Figure 5: Time-dependence of UV-vis spectra of the copper(II) complex of Triapine (a) and $\mathrm{H}_{2} \mathrm{NNMe}_{2}$ (b) in the presence of 50 eq ascorbate at $\mathrm{pH} 7.4$ under $\mathrm{O}_{2}$-free condition. The green line shows the spectrum of the sample before mixing the reagents. $\left(\mathrm{c}_{\text {copper(II) }}=25 \mu \mathrm{M}, \mathrm{c}_{\text {ligand }}=25 \mu \mathrm{M}, \mathrm{c}_{\text {ascorbate }}=1250 \mu \mathrm{M}, \mathrm{pH} 7.4\right.$ (HEPES)) 
MES-SA

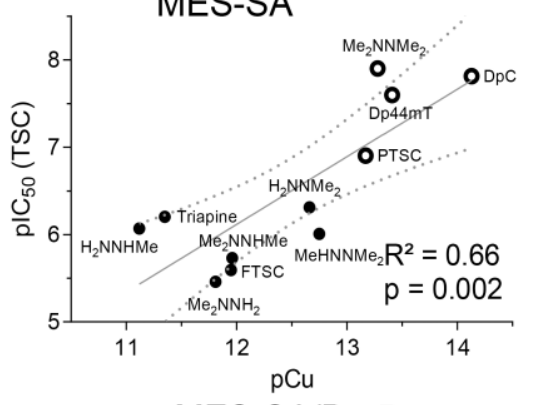

MES-SA/Dx-5
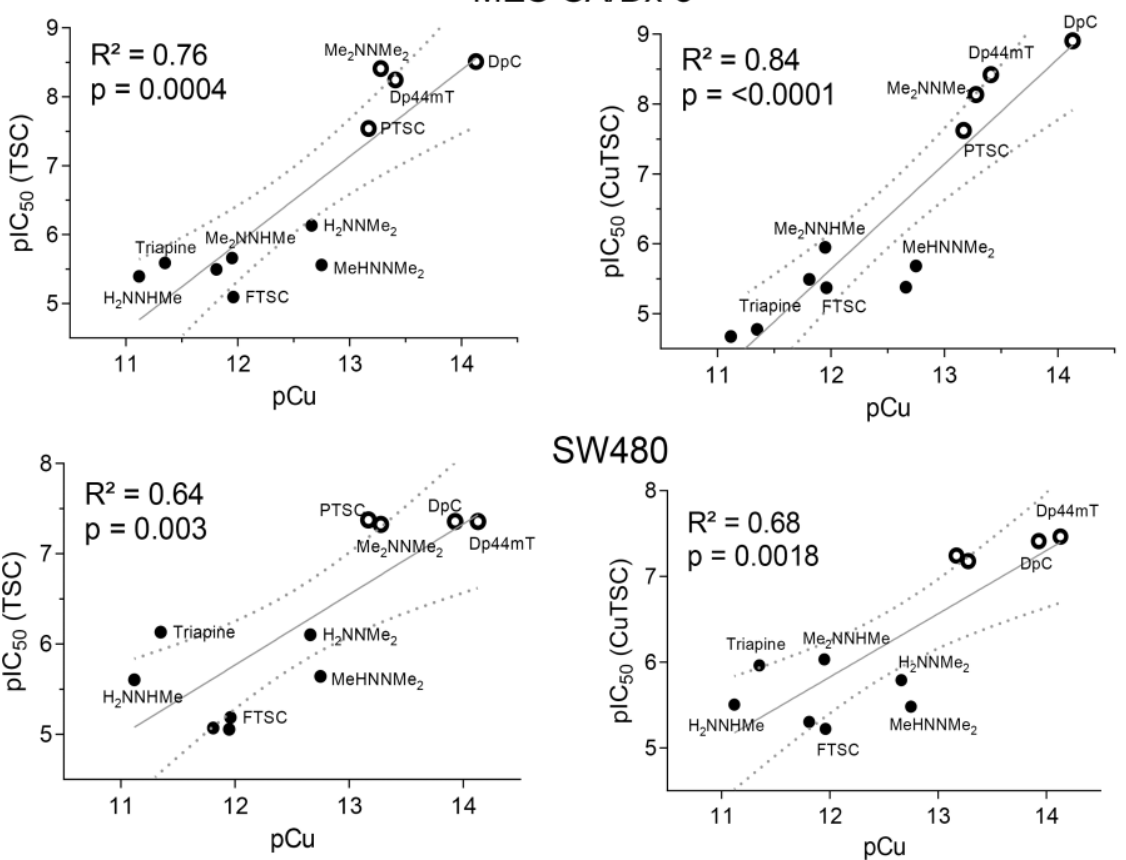

SW480

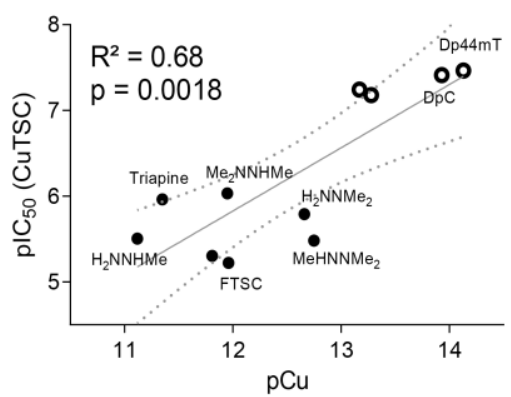

Suppl. Figure 6: Correlation of $\mathrm{pCu}$ values, representing copper(II) complex stability, to anticancer activity ( $\mathrm{plC}_{50}$ values) of the metal-free TSCs or the copper(II) complexes in MES-SA cells, MES-SA/Dx5 or SW480 cells. Correlation with $\mathrm{Cu}-$ TSC in MES-SA cells is shown in Figure 2E. $R^{2}$ and $p$ values have been calculated using Graph Pad prism software. 
A
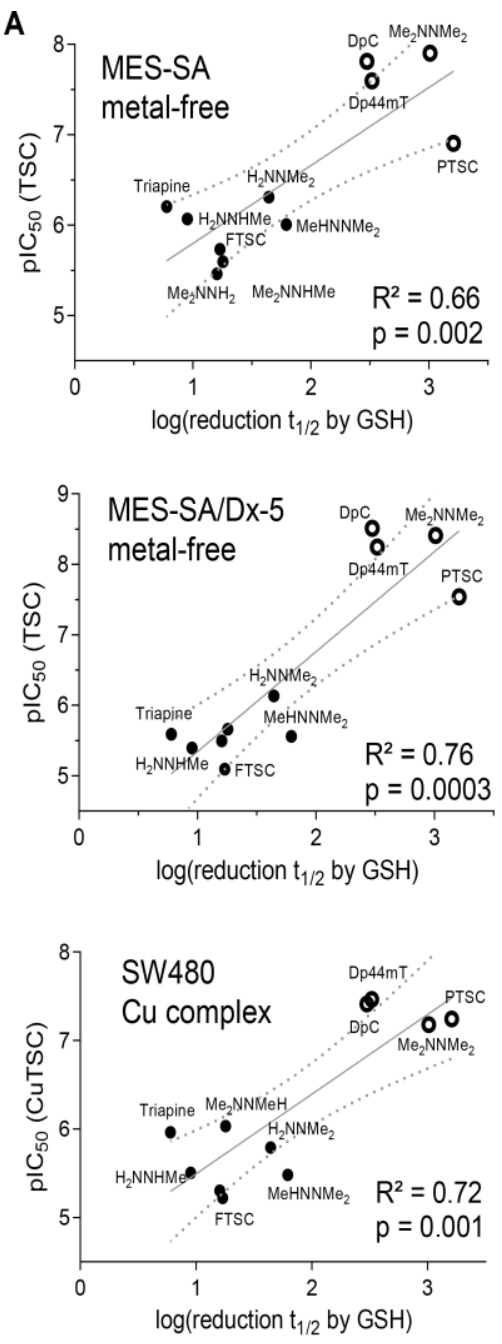
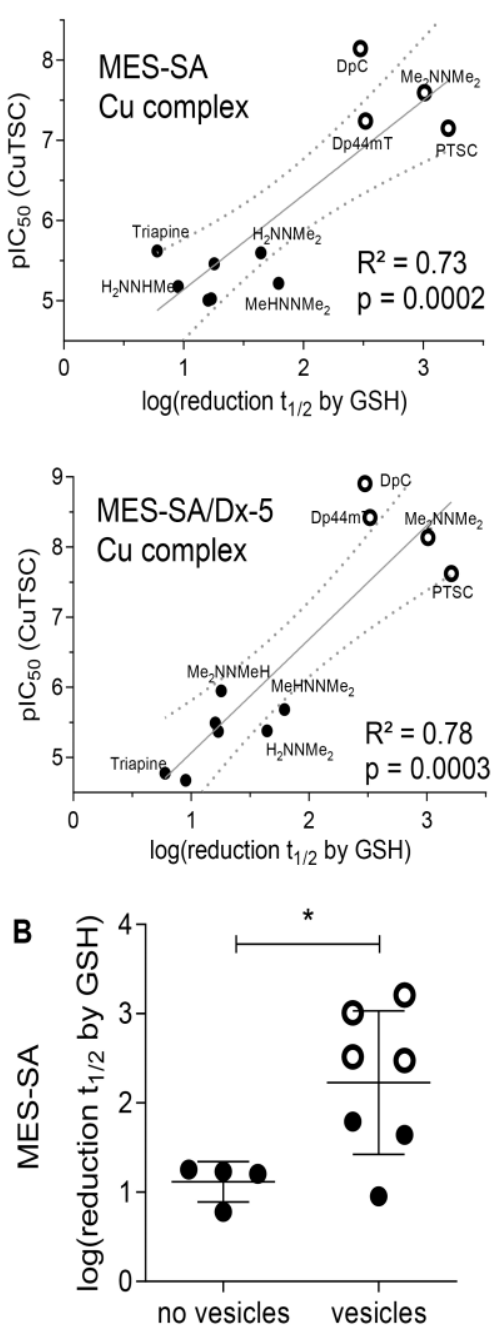

Suppl. Figure 7: A: Correlation of the logarithmic reduction half-life of the TSC copper(II) complexes reduced by GSH to anticancer activity ( plC $_{50}$ values) of the metal-free TSCs or the copper(II) complexes in MES-SA cells, MES-SA/Dx5 or SW480 cells. $R^{2}$ and $p$ values have been calculated using Graph Pad prism software. B: Grouping of the compounds by vesicle induction (threshold: 10\%) at 1 $\mu \mathrm{M}$ treatment metal-free ligand for $24 \mathrm{~h}$ in MES-SA cells showed a slower copper(II) complex reduction by GSH in vesicle-inducing TSCs. Significance between groups was calculated by two-tailed T-test using GraphPad Prism software ( $\left.{ }^{*} p<0.05\right)$. Open symbols indicate nanomolar-active TSCs. 


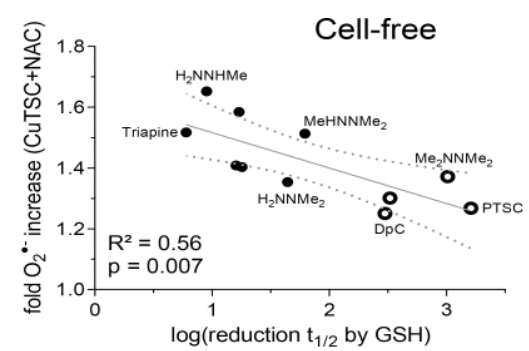

Suppl. Figure 8: Correlation of logarithmic reduction half-life of the TSC copper(II)

complexes reduced by GSH to the superoxide production by the TSC copper complexes in the presence of NAC. $R^{2}$ and $p$ values have been calculated using Graph Pad prism software. 
GO_REGULATION_OF_RESPONSE_TO_OXIDATIVE_STRESS

\begin{tabular}{lcccccccc}
\hline TSC vs ctrl & rank & size & ES & NES & nom p-val & FDR q-val & FWER p-val & $\begin{array}{l}\text { rank at } \\
\text { max }\end{array}$ \\
$\mathrm{Me}_{2} \mathrm{NNMe}_{2}$ & 678 & 59 & 0.49 & 1.49 & 0.022 & 0.101 & 1.000 & 2697 \\
Triapine & 988 & 59 & 0.39 & 1.25 & 0.142 & 0.347 & 1.000 & 2664 \\
\hline
\end{tabular}

Suppl. Figure 9: Gene set enrichment analysis of Gene Ontology terms revealed no significant upregulation of response to oxidative stress gene sets after $\mathrm{Me}_{2} \mathrm{NNMe}_{2}$ or Triapine treatment of SW480 cells, as depicted by the high FDR and FWER values of the most relevant gene set "regulation of response to oxidative stress". 
A

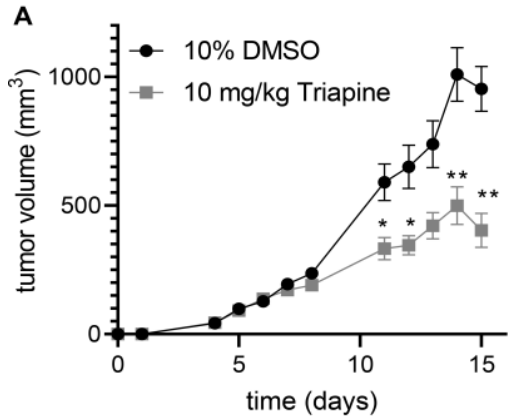

B

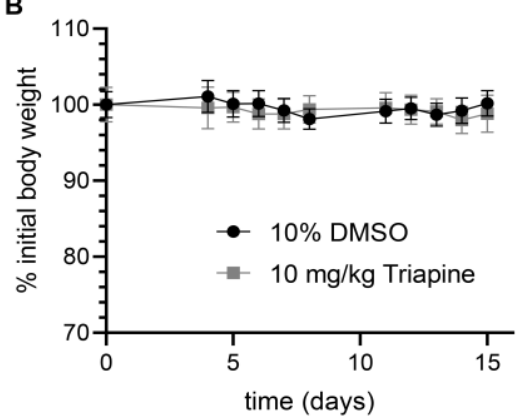

Suppl. Figure 10: Female Balb/c mice bearing subcutaneous CT-26 tumors were treated with solvent $(10 \% \mathrm{DMSO})$ or Triapine $(10 \mathrm{mg} / \mathrm{kg})$, p.o. for 5 consecutive days a week for two weeks. A: Tumor size was assessed regularly by caliper measurement. Tumor volumes (means \pm standard errors of the mean, SEM), calculated using the formula: length $\times$ width $^{2} / 2$. Significance to solvent group was calculated by mixed-effect model (REML) with Dunnett's multiple comparison test $\left({ }^{* *} p<0.01\right)$. B: Body weight changes in percent to initial body weight is given as means \pm standard errors of the mean, SEM. 
A

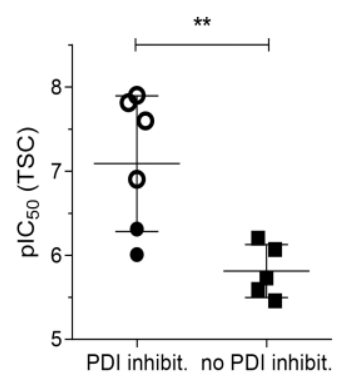

B

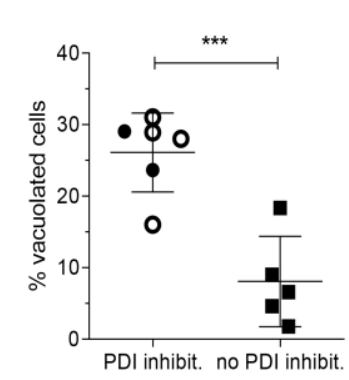

MES-SA/Dx5

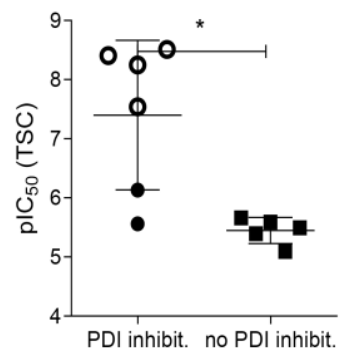

PDI inhibit. no PDI inhibit.

Suppl. Figure 11: TSC complexes that inhibit PDI above levels of copper ions alone also showed higher anticancer activity in MES-SA or MES-SA/Dx5 cells (A) and vesicle formation in MES-SA cells (B). 

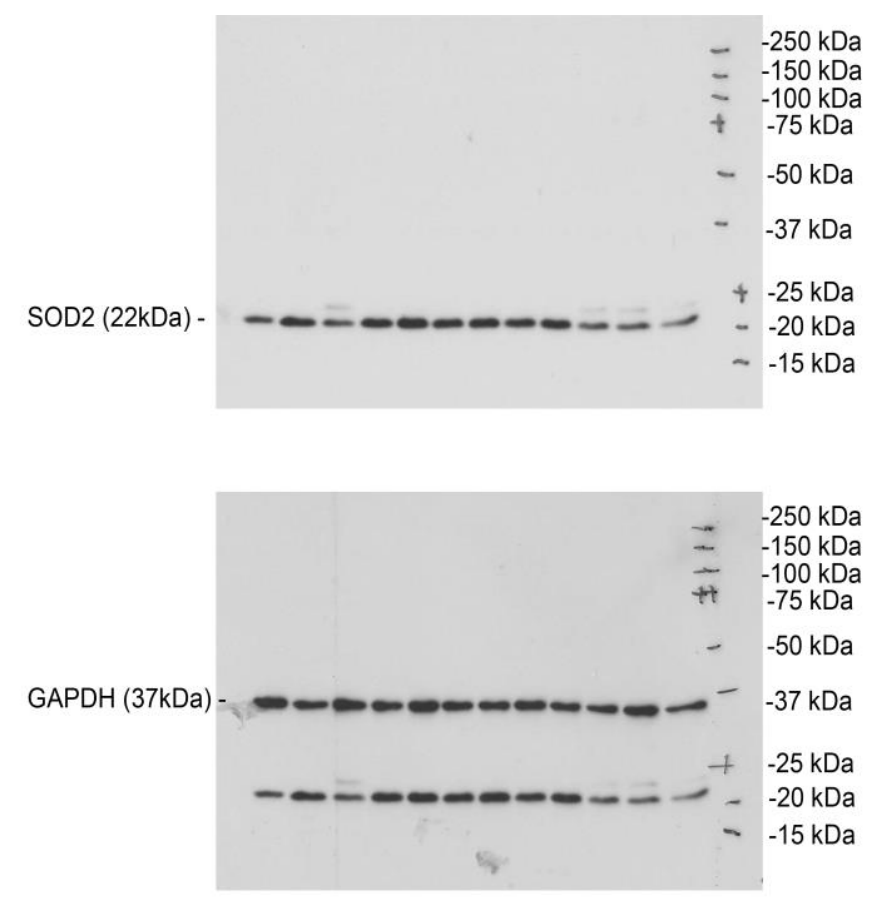

Suppl. Western: Whole film of Western blot analysis shown in Figure 4 of the main manuscript. 